\title{
The Geography of Unconventional Innovation
}

\author{
Enrico Berkes and Ruben Gaetani*
}

February 15, 2015

\begin{abstract}
Using a newly assembled dataset of narrowly georeferenced patents, we document that innovation activity is not as concentrated in densely populated areas as commonly believed: suburban regions are responsible for a substantial share of the innovation produced. Nevertheless, high-density areas disproportionately generate innovation of unconventional nature. We provide causal evidence for a mechanism that can generate this pattern: unconventional ideas are more likely to emerge when people interact in a dense and technologically diverse environment. An endogenous growth model with heterogeneous innovation and spatial sorting reveals that optimal place-based policy in the U.S. would foster urbanization to promote unconventional ideas, at the cost of sacrificing growth and inducing higher congestion.
\end{abstract}

JEL Classification: O33, O40, R11, R12

*Northwestern University, Department of Economics. 2001 Sheridan Road, Evanston, IL, 60208. Enrico Berkes: enrico.berkes@u.northwestern.edu; Ruben Gaetani: gaetani@u.northwestern.edu. We thank for their comments Treb Allen, David Berger, Matthias Doepke, Marty Eichenbaum, Ben Jones, Lorenz Kueng, Lee Lockwood, Guido Lorenzoni, Kiminori Matsuyama, Nicola Persico, Giorgio Primiceri, Jorg Spenkuch and seminar participants at the Conference of Swiss Economists Abroad 2014 and Northwestern Macro Lunch. Comments are welcome, errors are ours. 


\section{Introduction}

Ever since Lucas (1988), the literature on economic growth and geography has postulated that population density catalyzes the flow of knowledge and is therefore central to the creation of new ideas. According to this hypothesis, innovation should cluster in high-density areas and cities should be a key engine of technological progress. We confront this intuition using narrowly georeferenced information on patenting in the United States. Our geographically disaggregated data show that the advantage of cities in the production of innovation is weaker than commonly believed. Suburban areas are responsible for a substantial share of aggregate innovation activity. However, we also find that high-density areas disproportionately generate innovation characterized by a high degree of unconventionality. This pattern, which to the best of our knowledge we are the first to document, reconciles the intuition that density fosters creativity with the empirical observation that the geographical origin of innovation in the U.S. is dispersed.

Creativity is central to scientific and technological progress. On the one hand, it constitutes the key driver of economic growth, being the foundation for the introduction of new products and more efficient production processes. On the other hand, it contributes to weed out inefficient producers from existing markets, providing a bedrock for creative destruction. However, creative ideas are neither the only nor the most important component of technological change. In fact, most of the innovation activity is highly conventional in nature, relies extensively on previous wisdom, and introduces minimal novel ideas.

In this paper, we focus on the role of economic geography in determining the creativity mix that an economy exhibits in its innovation landscape. In particular, we study how the heterogeneous nature of innovation interacts with economic geography and analyze how this interaction affects the static and dynamic properties of the economy. We document a robust positive relationship between urbanization and atypicality in innovation. In particular, we find that higher density of population is associated with significantly higher propension for unconventional innovation. We analyze how economic and demographic characteristics contribute to this pattern. We then provide suggestive and causal evidence of the underlying mechanism: density favors diversification over specialization and unconventional ideas emerge from the informal interaction of people coming from different knowledge backgrounds.

Consensus is spreading among economists that the growth prospects of advanced countries increasingly depend on their ability to produce valuable innovation. This rapid shift in the pattern of comparative advantages in the world economy is imposing dramatic changes to the economic geography of rich countries (Moretti, 2012). In the United States, innovation hubs are flourishing both in high-density urban centers (e.g., Seattle and San Francisco) and lowdensity areas (e.g. Durham, NC). According to a recent study by Katz and Wagner (2014), innovation districts are developing around under-utilized areas of old industrial clusters in cities 
like Cleveland, Detroit and Pittsburgh. Place-based policies, aimed at attracting firms and workers with high innovation potential, have become today one of the main tools of economic policy for local governments. In this paper, we show that economic geography has a first order effect on the incentives to carry out different types of innovation. An important implication of this finding is that the spatial sorting of innovation activities should be taken into account for the correct design of such policies. In addition to the traditional scope of promoting the development of regions with high potential and low resources, place-based policies shape the composition of aggregate innovation by affecting its conventionality mix.

For a long time, the existence of localized knowledge spillovers in densely populated cities has been postulated and empirically assessed by the literature on urban economics and innovation, starting from the work of Glaeser (1999) to the more recent contributions of Combes et al. (2012) and Davis and Dingel (2012), among others. Our main findings shed light on the exact nature of such spillovers. A close look at the geographical origin of innovation in the United States reveals that a surprisingly high share of innovation activity takes place in low-density areas. This fact raises some challenges to the common intuition, derived from Lucas (1988) and preeminent in the literature, that high-density areas facilitate the flow of ideas and promote both the creation and diffusion of knowledge. We solve this puzzle by allowing innovation to be intrinsically heterogeneous. The advantage of urban areas is in generating cross-field technology spillovers which are the base for unconventional innovation.

We start our analysis by collecting the full text records of all the patents issued by the United States Patent and Trademark Office (USPTO) between January 2002 and August 2014. For each patent in the universe, we collect information on the relevant technology class and construct a database with the entire network of citations from and towards each patent. To construct our measure of conventionality, we follow Uzzi et al. (2013, UMSJ henceforth) in extracting information from the entire network of citations to identify citation patterns with a high degree of novelty. Our algorithm classifies a patent as unconventional if it cites a mix of technology classes that are observed together in the data less often than what a pseudo-random allocation of citations would predict. Consistently with UMSJ, we find that the most relevant share of innovation is highly conventional in nature, but patents that display the intrusion of highly unconventional citation pairs (a low "tail conventionality") are more likely to become hit patents. This motivates us to use tail conventionality to measure the creativity content embedded in each patent. UMSJ apply an analogous methodology to study unconventionality of scientific publications and find very similar patterns. This surprising similarity suggests, as conjectured by UMSJ, that the process of knowledge creation follows universal patterns independently of its nature of academic or applied research.

Whenever available, we retrieve information on the US location of the original assignee. If 
the latter is not available (e.g., the patent does not display an institutional assignee) we use the residence of the primary inventor. We construct an automatized algorithm to georeference each patent at the County Sub-Division (CSD) level, which is the finest geographical partition of the US territory univocally identifiable through the information contained in the patent's full text. For each CSD, we retrieve demographic and economic data from the Census Bureau provided by the National Historical Geographic Information System.

Our main empirical finding is that the creativity content of innovation is positively correlated with the density of population. This relationship is statistically and economically significant, as well as extremely robust to a variety of specifications. First, we show that this result is not driven by the geographical sorting of large (publicly traded) firms in suburban areas, although we find that most of the innovation activity of large firms is indeed highly conventional. Second, we show that this result is not driven by any of the four most densely populated groups of CSD's (i.e., New York City, Boston, San Francisco and Chicago). Third, we control for the level of income and the skill mix of the local population. Median income is negatively correlated with creativity, while the share of college graduates has a significant positive impact on our measure of novelty. Moreover, we find that density is a strong predictor of the success of a patent (measured in terms of citations received), even after controlling for conventionality. In other words, the spillovers that density catalyze are significant independently of the nature of the innovation activity. This suggests that the geographical sorting is rather the result of a balance between high costs (congestion, high rents, etc...) and high returns from unconventional ideas.

A candidate mechanism for explaining these patterns is that density favors diversification over specialization, and provides a demographic environment that induces informal interactions among people from diversified backgrounds. This results into inventions that build upon uncommon combinations of knowledge. In order to provide evidence for the presence of such mechanism, we test the ancillary hypothesis of the existence of local bias in drawing ideas to embed into inventions. First, we show that places with a given technology mix are more likely to produce patents that display citations drawn from the same technology mix. Second, to accommodate potential endogeneity concerns, we perform a diff-in-diff exercise and show that, upon arrival of a new a firm in a given location, pre-existing companies in the same location tend to shift the knowledge base of their inventions towards the field of the new firm. To the best of our knowledge, this paper is the first to provide causal evidence of the existence of inter-sectoral local knowledge spillovers.

The spatial sorting of innovation that we document is likely to emerge as an equilibrium outcome that contributes to explain, rather than simply being determined by, economic and demographic variables. To interpret this two-way interaction and study its macroeconomic implications, we construct a spatial equilibrium model with endogenous growth and heterogeneous 
innovation. Unconventional ideas generate high returns as they allow to acquire monopoly power over a product line, replacing the previous producer. Conventional ideas marginally improve existing products and endogenously display decreasing returns. The creation of unconventional ideas requires two innovators from different fields to combine their knowledge. However, people from different backgrounds cannot interact in a formal environment (e.g., research departments or established firms), and the only way for them to interact is through informal channels. This makes the search of a research partner costly. Density facilitates the search, but comes at the cost of high rent and high congestion. Conventional innovation, that does not benefit from informal interactions, relocates towards low-density, low-rent, specialized areas.

The model highlights that the locational choice of innovators determines the degree of creative and incremental research and affects both the growth rate of output and the static allocation of resources. When choosing the optimal level of urbanization, a constrained planner strikes a balance among growth, efficiency and congestion costs. A calibration exercise using US data reveals that a planner would increase urbanization to boost creative destruction, reduce the monopoly distortion and improve the static allocation of resources in the economy. This would come at the cost of lower growth and higher congestion costs.

In our last exercise, we look at the implications of an increase in the supply of conventional innovation from emerging economies. Over the last ten years, the share of patents issued by the USPTO with an assignee from China and India has increased tenfold. As we show, these patents are characterized by a markedly conventional nature. The model shows that the initial inefficient allocation becomes increasingly costly in terms of welfare when an exogenous flow of conventional ideas hits the the economy if moving costs prevent people from relocating. We conclude by arguing that technological globalization can rationalize the observed emergence of urban policies and spontaneous trends that are changing the geography of innovation in the United States.

\section{Related Literature}

This paper is mainly related to three strands of literature. First, we contribute to the empirical literature on the estimation of local knowledge spillovers. The importance of localization and geography for the spreading of knowledge, which dates back to Marshall (1890), ${ }^{1}$ has been the subject of extensive empirical study in recent years since Lucas (1988) and Krugman (1991) seminal papers on economic development and economic geography. Jaffe et al. (1993) analyze the network of patents and find that patent citations display a significant bias towards

\footnotetext{
${ }^{1}$ In Marshall's famous words: "When an industry has thus chosen a locality for itself, it is likely to stay there long: so great are the advantages which people following the same skilled trade get from near neighborhood to one another. The mysteries of the trade become no mysteries; but are as it were in the air, and children learn many of them unconsciously."
} 
patents that were produced in the same state and metropolitan area. Audretsch and Feldman (1996) and Audretsch and Stephan (1996) analyze the geographical concentration of production and innovation activities and find evidence of substantial complementarities between the two. Feldman and Audretsch (1999) look at the pattern of diversification and specialization in the localization of innovation and find that geographical clustering of complementary industries is more conducive to knowledge spillovers than the agglomeration of specialized activity. The topic of localized knowledge spillovers has interested economists as well as other social scientists, such as Porter (1990) and Saxenian (1994). Florida and Gates (2001) find that in US cities the degree of cultural diversity is positively correlated with success in high-tech industries. We contribute to this literature by explicitly considering how local innovation activity affects the composition of the knowledge base upon which inventors build new ideas. This approach puts particular emphasis on inter-field technology spillovers. Our main finding, namely, that density of population is positively correlated with unconventionality in innovation, is in line with the findings in a recent paper by Packalen and Bhattacharya (2015), in which the authors show that inventions that originate in high-density areas build upon newer concepts than the ones that originate from smaller cities.

Second, this paper contributes to the theoretical literature on spatial equilibria and knowledge spillovers. One of the first models of knowledge flow in a spatial setting is due to Glaeser (1999). Davis and Dingel (2012) develop a model in which productivity in cities is fostered by informal interactions of people living in a densely populated environment. In their setting, the spatial equilibrium is determined by the comparative advantage of high-skilled individuals in an environment with high learning opportunities. In our setting, we consider individuals that are homogeneous in all respects but their knowledge background and density plays the peculiar role of favoring informal interactions among people from different fields. As in Berliant and Fujita (2011), knowledge diversity is a key component of growth in our setting. In addition, we provide a microfoundation for how diversity can be combined in unconventional ideas through a mechanism that is compatible with our empirical findings.

Finally, this paper is related to the literature on endogenous growth and heterogeneous innovation. Akcigit and Kerr (2010) develop a model with heterogeneous firms in the spirit of Klette and Kortum (2004) and explicitly allow for the possibility to carry out exploration R\&D to acquire new product lines and exploitation R\&D to improve existing ones. In our model, we identify exploration R\&D with unconventional innovation. This choice is based on the empirical observation that unconventional patents have a substantially higher technological impact than conventional ones. From a technical point of view, our model closely resembles Peters (2013) in assuming limit pricing and Cobb-Douglas final good aggregator. This setting has the advantage of allowing a simple decomposition of welfare into a static and a dynamic component. However, 
we interpret the acquisition of product lines (entry) specifically as resulting from unconventional ideas. The taxonomy of innovation that we assume in our setting resembles the one proposed by Acemoglu et al. (2014) who distinguish between radical and incremental innovation and study how cultural factors in a cross-section of firms (and countries) affect the choice between the two.

\section{Data}

For our analysis, we use a selected sample from the universe of patents granted by the US Patent and Trademark Office (USPTO) from January 2002 to August 2014 for a total of 2,275,752 patents. We rearrange these patents by filing year and consider the period that goes from 2000 to 2010. More than $94 \%$ of all the grants in our dataset were filed in this time period. Table B.1 in Appendix reports the number of patents by filing year. Every patent is then associated to one of 107 IPC patent classes. Since sometimes multiple IPC classes are associated to a single patent, we do this by using the following statistical procedure. The USPTO associates to each grant a unique main class according to the US patent classification (USPC) system which contains 438 classes. For each of these main classes, we collect all the IPC classes that are associated to them in the universe of patents and we take the one that recurs more often. This way, we are able to build a one-to-many function that maps every USPC class to a single IPC class. We also gather the class of every patent cited by each patent (up to a maximum of 1,500 citations given) as well as the class of all the patents that cite that patent (up to a maximum of 1,500 citations received).

With these data at hand, we build a measure of conventionality for each patent. This measure compares the empirical frequency with which every citation pair occurs in the data with the frequency that one would expect to observe if patents were cited at random, keeping the citation network from class to class intact. We discuss the details of our measure in Section 2.1 .

Every patent is geolocated following a hierarchical rule: If the patent file reports the name of an assignee then we assign to the patent the geographical coordinates of their location; if the file does not report any assignee or its address is missing, the patent is geotagged according to the location of its first inventor, otherwise of its second inventor and so on until we are able assign a location to each patent. For the purposes of our paper, we discard all the patents located outside the United States (patents from Puerto Rico and Virgin Islands were discarded, as well). At the end of this procedure, we are left with a total of 1,058,999 patents filed by US physical or juridical persons over 11 years.

For the demographic data, we used the public data from the Census as well as the 5-year American Community Survey (ACS). The whole analysis is performed at a County Sub-Division 
(CSD) level which is the finest geographical unit that we are able to identify uniquely by intersecting the location data available in the patents and the data available from the Census. Since demographic data at this level of disaggregation are only available every 10 years, the values between 2000 and 2010 of the demographic variables were interpolated assuming a constant growth rate throughout the years.

\subsection{The Conventionality Score (c-score)}

In this section, we describe how we measure conventionality in the network of patents and we provide a description of the properties of our measure. Many studies in the literature on macro innovation follow Hall et al. (2001) and calculate the originality of a patent according to:

$$
\operatorname{orig}_{j}=1-\sum_{i \in I} s_{i j}^{2}
$$

where $s_{i j}$ is the share of citations to patents of class $i$ given by patent $j$. This metric, that captures the dispersion of citations in patents, has the major shortcoming that it weights every citation class the same. So, a patent that cites, say, computing and cryptography, is considered as original as a patent that cites, say, computing and footwear. In order to overcome this problem, we follow the methodology proposed by Uzzi et al. (2013) who study atypical citation patterns in the universe of scientific papers. We modify the algorithm to fit the specificity of patent data. First, for every citation pair we calculate its frequency in the observed data. Second, We calculate what is the frequency with which one would expect to observe a citation pair if the citations were assigned pseudo-randomly to patents. We do this in a way that keeps the network of citations from class to class intact. Finally, the conventionality score (c-score) is computed for each class pair as the ratio of the empirical and pseudo-random frequency:

$$
c(i, j)=\frac{\text { freq }_{\text {emp }}(i, j)}{\text { freq }_{\text {rand }}(i, j)}
$$

A value of $c$ above 1 means that in the data we observe classes $i$ and $j$ cited together more often than what one would expect if the citations were assigned pseudo-randomly. We interpret this as a sign of conventionality. On the other hand, a ratio below 1 indicates that classes $i$ and $j$ are observed in the data less often than what one would expect at random. In this case, we say that the invention is unconventional. More details on the algorithm are provided in Appendix.

This measure allows us to compare each citation pair against the whole network of patent references and identify which citation pattern makes a patent original or conventional. To this end, we associate to each patent an entire distribution of c-scores, one for each pairwise combi- 


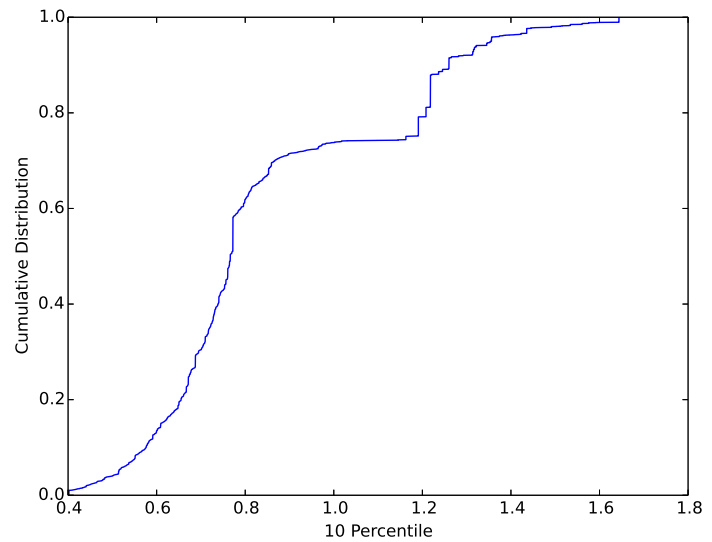

(a) cumulative distribution of the 10th percentile of the (b) cumulative distribution of the median of the c-score c-score distribution over all patents.

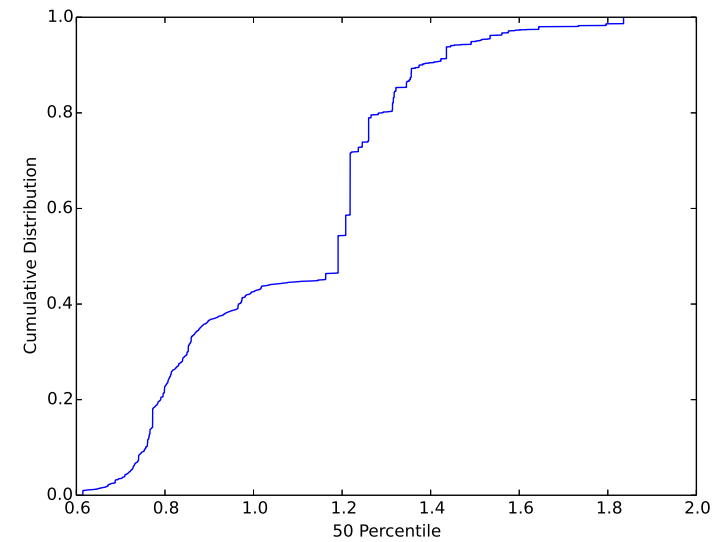

distribution over all patents.

Figure 2.1: Cumulative distribution of the 10th and 50th percentiles of the c-score

nation of references the patent displays. ${ }^{2}$ Figure 2.1 shows the cumulative distributions of the 10 and 50 percentile, respectively, in the universe of patents. By construction, the distribution of the 10 percentile is shifted to the left (less conventionality) compared to the one of the median citation pair. In particular, about $70 \%$ of the patents cite an atypical pair at the 10 percentile, whereas only $40 \%$ of them have an atypical median citation pair.

Figure 2.2 is a graphical representation of the symmetric c-score matrix. Each pixel represents a citation pair and it is colored based on its c-score. For example, the pixels on the diagonal report the scores of the a citation pair $(x, x)$. We use a chromatic scale in which red denotes very conventional pairs, white denotes pairs that occurs just as often as in their random frequency and blue denote very unconventional pairs. There are two main patterns that are evident when looking at the figure. First, citation pairs on the diagonal tend to be more conventional than other citation pairs. This is exactly what we would expect from a conventionality measure: once a patent cites a certain class, it is likely that is going to cite the same class again since that class probably plays a role in the patent development. Second, around the diagonal there are some clusters of conventionality. This happens because the system of classification tends to assign close labels to classes that are technologically close. For example, classes 1 through 16 group all the patents related to human necessities. It is not surprising then that a citation that falls in that group is likely to appear with another citation that falls in the same group.

Figure 2.3 shows the CSD's in the areas around four major US urban centers (namely, Chicago, New York, San Francisco and Boston). Each CSD is colored according to the average

\footnotetext{
${ }^{2}$ For example, a patent that lists 4 references, from classes $\{A, A, B, C\}$ will be associated with 6 c-scores, one for each pairwise combination $((A, A) \times 1,(A, B) \times 2,(A, C) \times 2,(B, C) \times 1)$.
} 


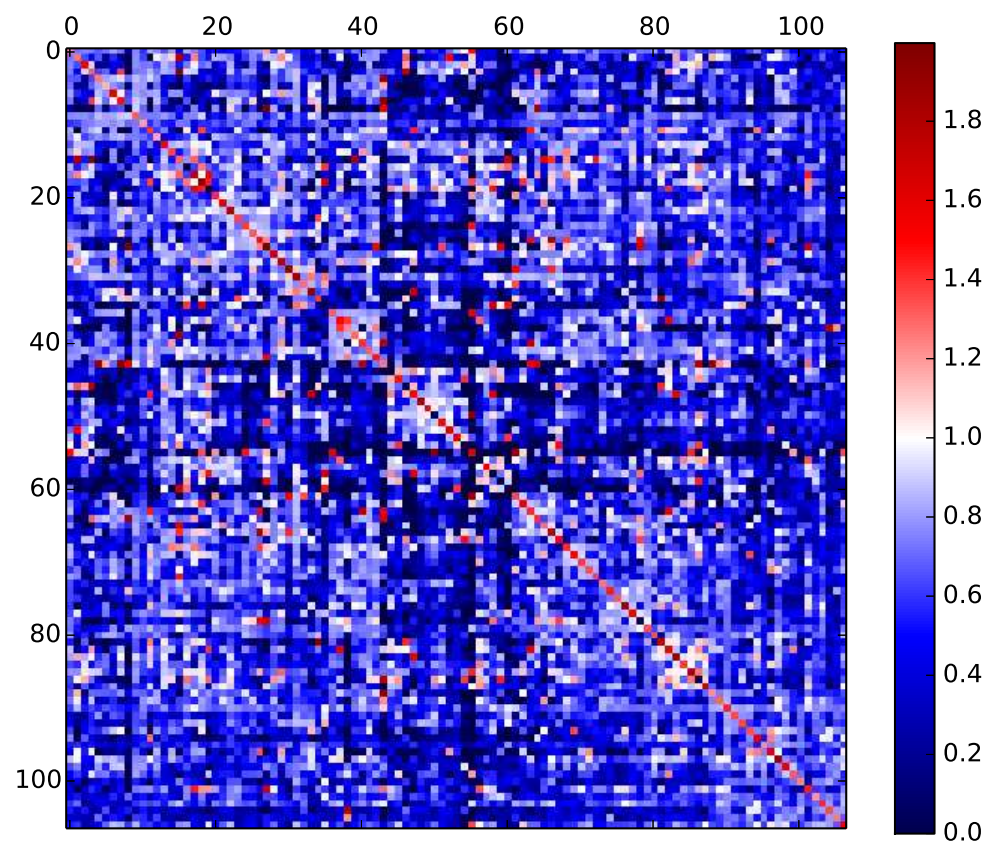

Figure 2.2: Every pixel in the matrix indicates a patent class pair. The more red the pixel the higher the c-score assigned to that class pair, the more blue the lower the c-score. Diagonal elements of the matrix show a clear red tendency compared to the rest of the matrix.

c-score of patents originated from there. The more blue (red) the color the more unconventional (conventional) the patents filed in that CSD. It is interesting to see how some areas that are commonly believed to be produce novel ideas are actually relatively conventional according to our measure. For example, the CSD that includes the Silicon Valley is as innovative as Manhattan and less innovative than Chicago. In fact, taking a closer look at the citation patterns of patents produced in the Bay Area, we note that patents in the IT class tend to cite mostly other IT patents and our measure classify them as relatively conventional. ${ }^{3}$ It is likely that the patents produced by innovative startups are much less in number than the ones filed by big IT companies and that is why the CSD's of the Bay Area seem less creative than Chicago. Our measure successfully captures the originality of places whose economy is dominated by startups. For example, Skokie, North of Chicago, is location of the Science + Technology Park, a startup incubator.

\footnotetext{
${ }^{3}$ Note that because of the way we built the c-score we do not take into account the time dimension. Since we only consider patents filed between 2000 and 2010, we think that it is reasonable to consider this time period as a snapshot of the innovation produced in the United States and analyze the data as if they represented a cross-section of the innovation environment. In order to properly take into account the time dimension and study how technology has evolved over time wold require a longer time series and we leave it for future work.
} 


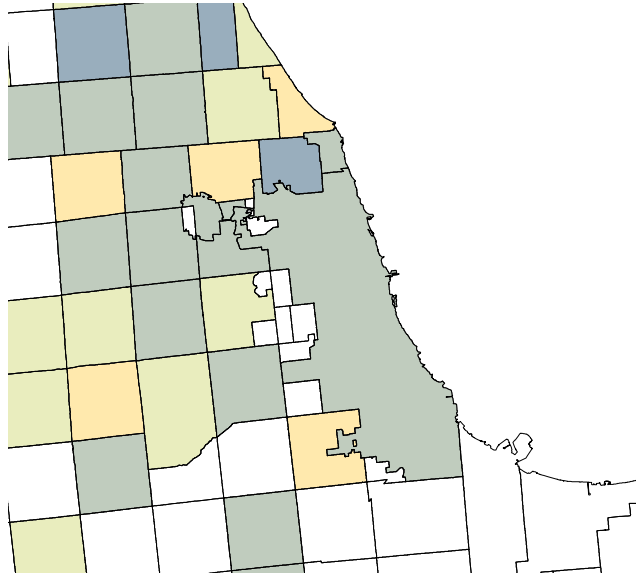

(a) Chicago

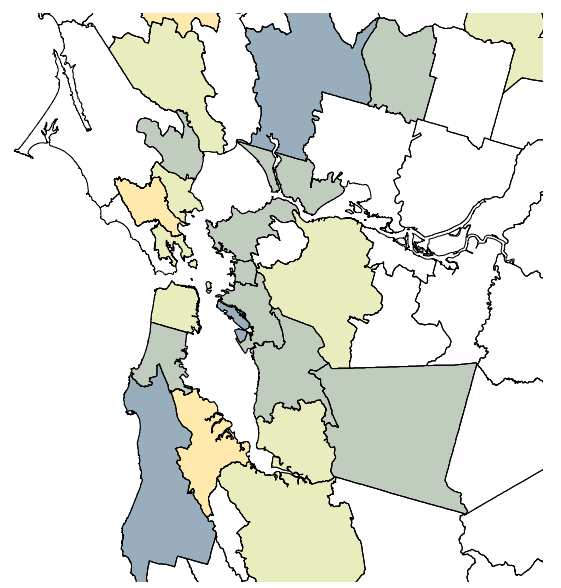

(c) San Francisco

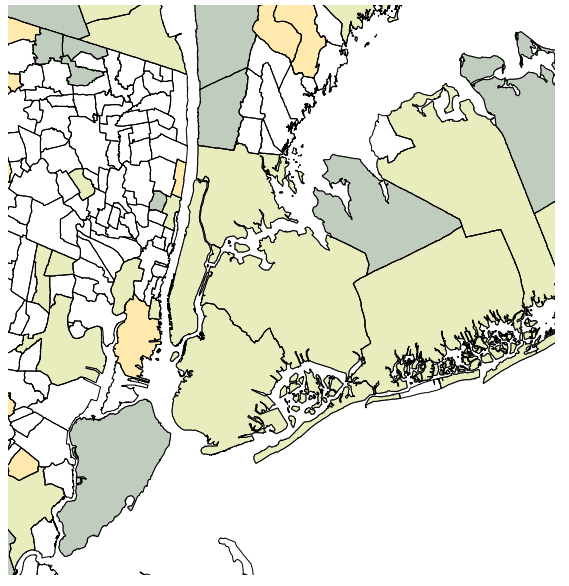

(b) New York

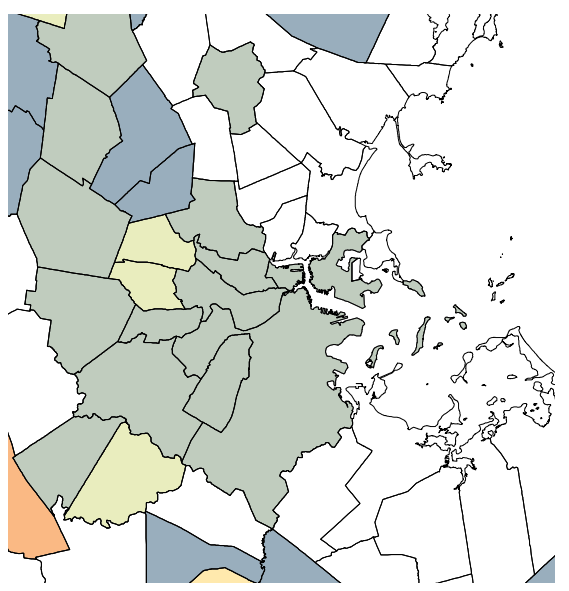

(d) Boston

Figure 2.3: Four major urban areas divided into CSD. The CSD colored with a color towards blue produced on average more unconventional patents, whereas CSD's leaning towards red produced more conventional patents according to the average c-scores of the patents filed there.

Finally, in the spirit of Uzzi et al. (2013), we check whether our measure is able to predict a patent's scientific impact. We define a hit patent as a patent which is in the top 5\% according to the number of citations received by patents in the same class and issued the same year. In order to do that, we first estimate a logit model of the form: ${ }^{4}$

$$
\operatorname{logit}\left(H_{T} T_{i c s t}\right)=\alpha+\delta_{t}+\delta_{c}+\delta_{\text {state }}+\beta \text { low } 10^{\text {th }} \text { perc } c_{i c t}+\text { medianCat } t_{i c t}^{\prime} \underline{\gamma}+\varepsilon_{i c s t}
$$

where $H I T_{i c s t}$ is an indicator variable which takes value 1 if the patent is a hit patent, low $10^{\text {th }}$ perc $c_{\text {ict }}$ is a dummy that takes value 1 if the 10th percentile of the c-score distribution of patent $i$ is below the median of class $s$ in year $t,{ }^{5}$ medianCat is a set of 4 indicators that take value 1 if the

\footnotetext{
${ }^{4}$ All the results presented hereafter are robust to using a linear probability model instead of a logit.

${ }^{5}$ We report the results with the 10th percentile because that is our preferred measure of unconventionality. We
} 


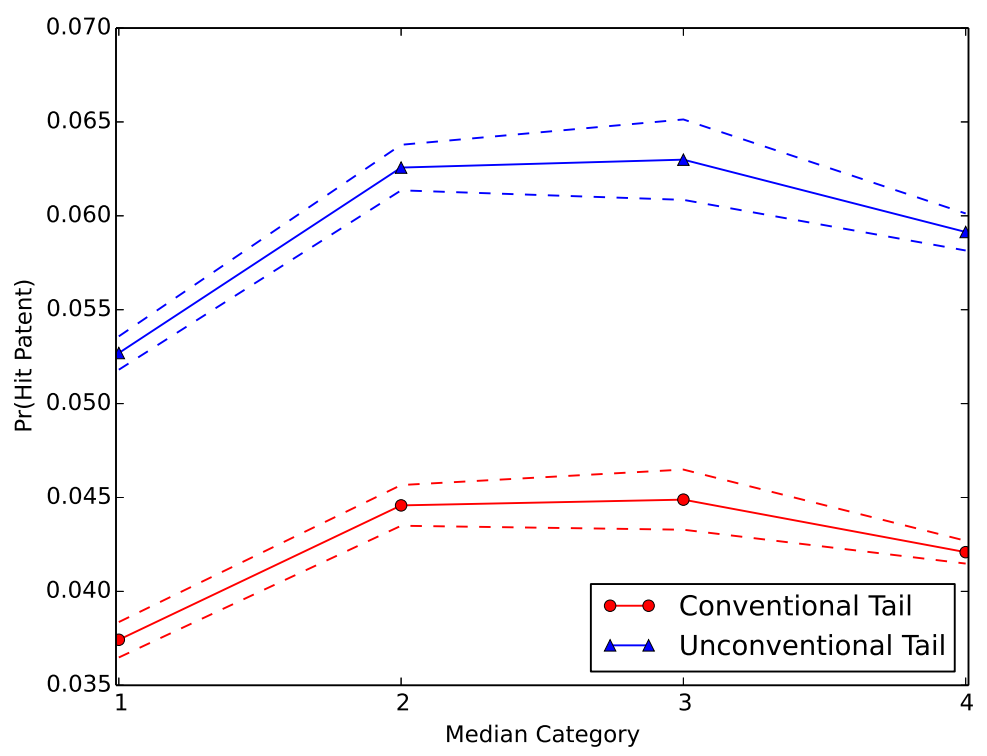

Figure 2.4: Marginal effect of having a conventional tail and being in a certain median category on the probability of being a hit patent.

median of the c-score distribution of patent $i$ falls into the first, second, third or fourth quartile of its class in year $t$, and $\delta_{t}, \delta_{c}$ and $\delta_{\text {state }}$ are year, class and state fixed effects, respectively. Figure 2.4 shows the joint marginal effects of the two variables on the probability of being a hit patent. The conditional probability of being a hit patent given these two measures ranges from $3.7 \%$ of a patent with a conventional tail of the c-score distribution and an unconventional median to $6.2 \%$ of a patent with an unconventional tail and a somewhat conventional median compared to a background probability of $5 \%$. Having an unconventional tail increases this probability by about 1.7 percentage points compared to a patent with the first decile of the c-score distribution above the median. On the other hand, the median of the distribution seems to have a smaller impact and it plays a role only going from the first to the second quartile, when it increases the probability of being a hit patent by about 1 percentage point. Surprisingly, our result is very similar to the one obtained by Uzzi et al. (2013) using scientific papers. Scientific papers tend to be cited more when they show an unconventional tail and a conventional median. This seems to suggest that the process of innovation, no matter if academic or technological, follows a universal pattern. Successful innovation has to be creative at the tail, but also well rooted in the already existing knowledge.

do so, because we believe that the 10th percentile is a more robust measure of tail unconventionality. However, all the results presented in this and next session go through when we use the minimum of the distribution instead of the 10th percentile. 


\section{Empirical Analysis}

In this section, we present some new empirical facts that try to disentangle the underlying relationship between the conventionality of the innovation output produced in a certain place and its demographic and economic characteristics. In particular, we want to study what distinguishes areas that produce unconventional innovation from areas that specialize in conventional innovation. To measure the degree of conventionality we use the 10th percentile of the c-score distribution of each patent. As we showed in the previous section, this metric successfully captures atypical combinations of technologies and is a good predictor of the success of a certain patent.

In a second moment, we empirically explore a possible mechanism that is at the core of the patterns that we observe. Taking the firm structure at the beginning of the sample in all regions as given, we interpret the arrival of a new firm in the subsequent years as an exogenous shock from their point of view. Performing a diff-in-diff analysis, we provide causal evidence that there is a mechanism of knowledge spillovers, like the one conjectured by Lucas (1988), at work.

\subsection{Stylized Facts}

In this Section, we present four stylized facts. In particular, we show that (i) A non-negligible share of innovation is produced in low-density areas; (ii) High-density areas are relatively more diverse; (iii) High-density areas tend to produce disproportionately more unconventional innovation, whereas CSD's outside urban centers tend to produce more conventional innovation. This correlation is not driven by median income, percentage of highly educated people living in the area, inequality or the fact that big, more conventional firms tend to sort in suburban areas; (iv) Density is a strong predictor of a patent's impact.

\section{Fact 1: A non-negligible share of innovation is produced in low density areas}

In the last decades, the literature on innovation and geography has postulated that cities constitute the right environment where the production of ideas should take place. It has been argued that one of the main reasons for people to cluster in cities (and suffer the inconveniences of urban life) in today's world is the constant exposure to ideas they can enjoy. However, a closer look to geographical origin of patents in the US suggests that low density area play a key role in the innovative process. About 43.3\% of the patents filed between 2000 and 2010 were produced in sub-counties with a population density below 1,000 inhabitants per square kilometer. These areas accounted for the $53.6 \%$ of the total US population in 2010. Even when we consider more sparsely populated areas, we still find that they are responsible for a sizable part of the innovation process of the country. Around $20.2 \%$ of the patents that were filed between 2000 and 2010 


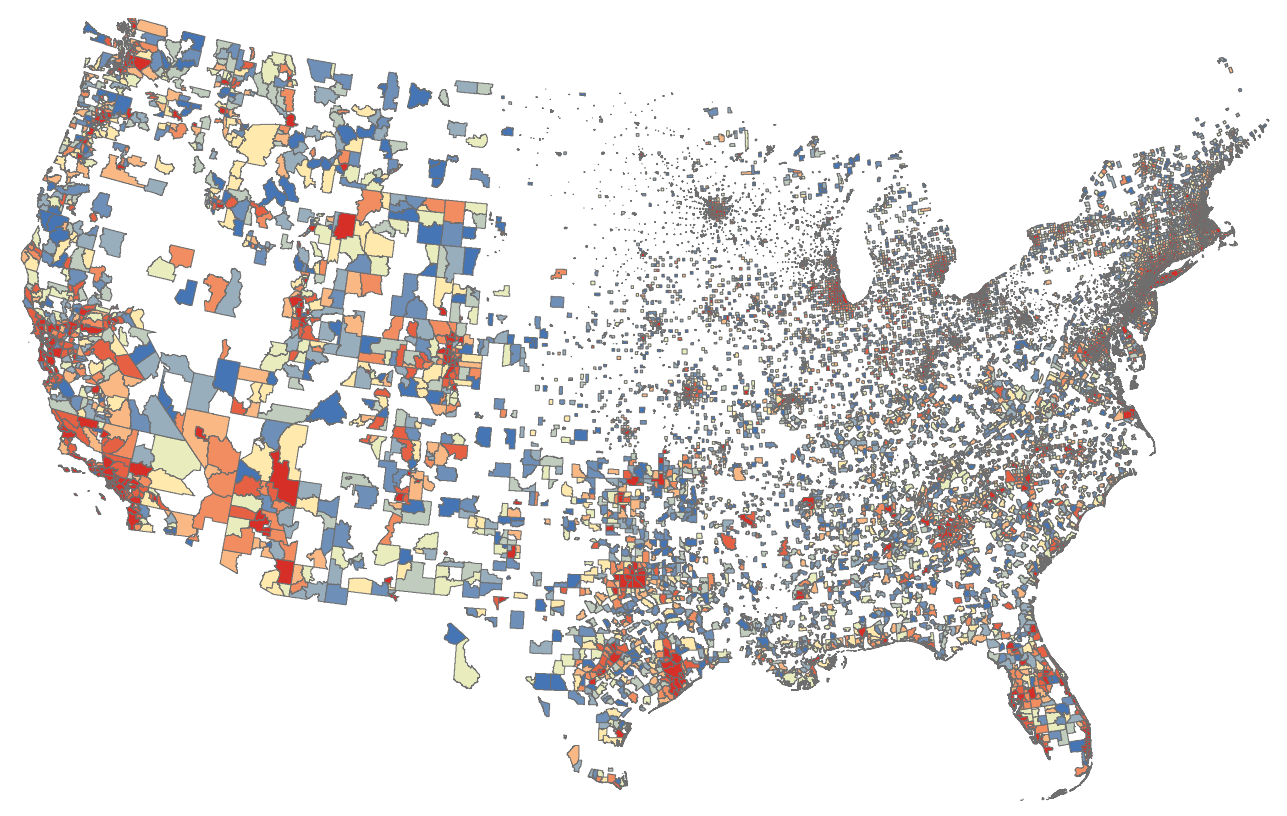

Figure 3.1: The figure shows a map of county sub-divisions in the United States. Each CSD is colored according to the number of patents produced weighted by the number of citations received. The more red the higher this value; the more blue, the lower. No patents have been filed in the CSD's that are missing in the map.

were produced in areas with a density below 500 people per square kilometer (that account for $31 \%$ of the total population). When we restrict attention to CSD's that produced at least one patent between 2000 and 2010, the relationship between patent per person and density of population becomes negative. One might be concerned about the quality of the patents produced in these areas. Weighting patents by the number of citations they receive, we still get that $41.1 \%$ and $18.1 \%$ of citation-weighted patents are produced in areas with a density below 1,000 and 500 people per square kilometer, respectively.

Figure 3.1 shows where innovation is produced across the United States graphically. We colored each CSD according to the number of citation-weighted patents produced. The more red (blue) the CSD the more (less) citation-weighted patents are produced there. We notice that there is certainly a tendency for patents to concentrate towards cities. However, from the map it is also clear that a big part of patents are produced outside urban centers. ${ }^{6}$ This pattern of innovation is puzzling when analyzed through the lens of the literature: If cities are the natural place where innovation occurs, why do observe such a big share of patents produced in low density areas? We try to reconcile this empirical finding with the common wisdom by qualifying what kind of innovation is produced in high-density areas compared to low-density ones.

\footnotetext{
${ }^{6}$ Because of the smaller dimensions of sub-counties on the East-coast, Figure B.1 in Appendix shows a magnified map of the region Boston-New York-DC.
} 


\section{Fact 2: High-density areas are relatively more diverse}

The next fact we discuss is less surprising, but still worth a formal empirical analysis. We show that the innovation output is more diversified in high density places. We proxy diversity through a variable built similarly to the Herfindahl index which is used as a measure of industry concentration and defined as:

$$
H_{s}=\sum_{c=1}^{107} s_{c s}^{2}
$$

where, in this case, $s_{c s}$ is the share of patents of class $c$ produced in CSD $s$. This measure is equal to one if only patents of a certain class are produced in a certain CSD. The smaller the relative share of each class, the smaller $H_{s}$.

In order to study the relationship between this metric and population density, we first partial out the state and year fixed effects as well as the total number of patents produced in a certain CSD. ${ }^{7}$ We then plot the relationship between the two variables using the approach developed in Chetty et al. (2013). The idea is to divide the variable on the $\mathrm{x}$-axis in $\mathrm{N}$ percentiles $(N=20$ in our case) and take the mean of the variable on the y-axis of the observations falling in that bin. Chetty et al. (2013) show that this methodology is able to capture graphically the correlation between two variables. $^{8}$ Figure 3.2 shows that there is a clear relationship between the two variables. Highly densely populated places also tend to produce a more diversified innovation output.

\section{Fact 3: Unconventional innovation locates in high-density areas}

We now study how innovation sorts in the territory based on its conventionality content. Figure 3.3 plots the relationship between the population density of a certain CSD and the 10th percentile of the median patent produced in the same CSD after having taking into account year and state fixed effects. The graph shows a staggering relationship between the median 10th percentile of the patents produced in a certain area and its population density. The more densely populated a certain area the smaller the measure of conventionality.

In order to study this relationship more formally, we run a set of regressions of the form,

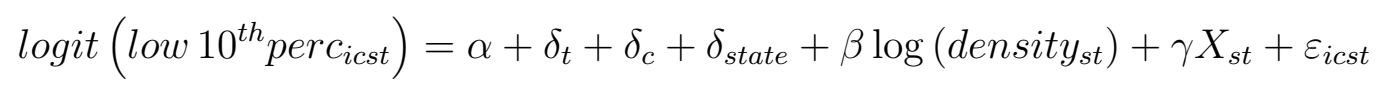

where low $10^{\text {th }}$ perc $_{\text {icst }}$ is a dummy variable that takes value one if the 10 th percentile of the c-score

\footnotetext{
${ }^{7}$ We partial out the total number of patents because our Herfindahl index-like measure tends, by construction, to assign a higher number to places that produce less patents. For example, a CSD that produces two patents can only receive values $\frac{1}{2}$ and 1 for $H_{s}$. Conversely, a CSD producing an infinite amount of patents will have an $H_{s}$ between 0 and 1. Results are unchanged if only the state and year fixed effect are taken out.

${ }^{8}$ See http://michaelstepner.com/binscatter/ for a more in depth discussion.
} 


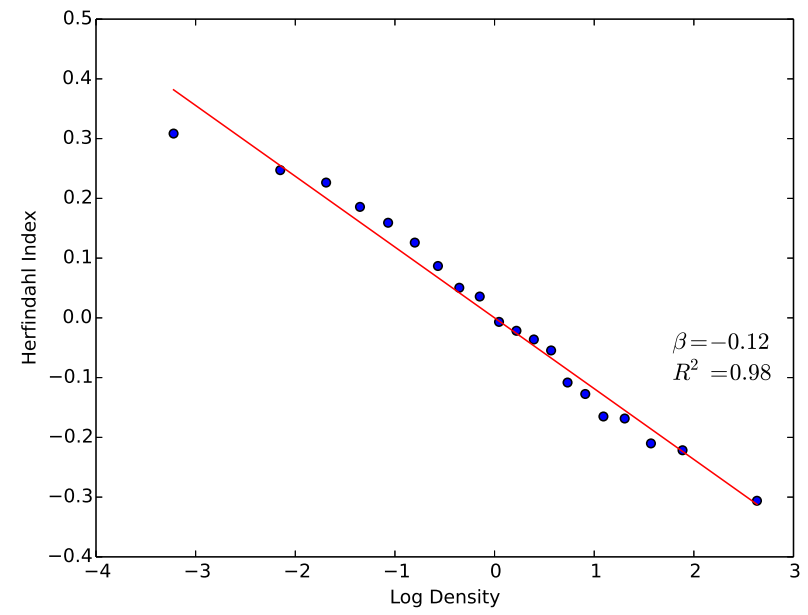

Figure 3.2: This figure represents the binned scatter plot of the relationship between population density and our measure of diversity. Both variables are first regressed on state and year fixed effects as well as the total number of patents produced in a certain CSD.

distribution of patent $i$ produced in CSD $s$ is below the median with respect to other patents of class $c$ filed in year $t,{ }^{9} \delta_{t}, \delta_{c}$ and $\delta_{\text {state }}$ are a set of year, class and state fixed effects, density $y_{s t}$ is the population density in CSD $s$ in year $t$ and $X_{s t}$ a set of controls at a CSD/year level. In our specification, we control that our results are not driven by $(\log )$ median income, the presence of high educated people, inequality or the fact that big, typically more conventional firms tend to place their research facilities outside the cities. We control for the latter with a dummy that takes value one if the firm that produced the patent is listed on the stock market. ${ }^{10}$ Table 3.1 reports the marginal effects of the logit regression. ${ }^{11}$ The estimates show a clear and positive relationship between population density and the probability of producing an unconventional patent. This relationship is significant and robust throughout all the specifications. The coefficient on median income is always negative and statistically significant. This is probably driven by rich residential neighborhood that are typically not the place where innovation is produced. Table B.2 in Appendix shows that these results are not driven by any of the four most densely populated urban centers. Finally, the coefficient of the traded dummy is negative suggesting that big firms tend to produce less risky, more conventional innovation. This is an interesting fact per se and would deserve further research. We leave this for future work.

\footnotetext{
${ }^{9}$ Remember that the lower the c-score the more unconventional the innovation contents according to our measure.

${ }^{10}$ Note that we used the dummy assembled by Kogan et al. (2014) that ends in 2006. We are working on extending this dummy for the subsequent years.

${ }^{11}$ All the regressions would quantitatively give the same results if we were to control for number of citations given by each patent.
} 


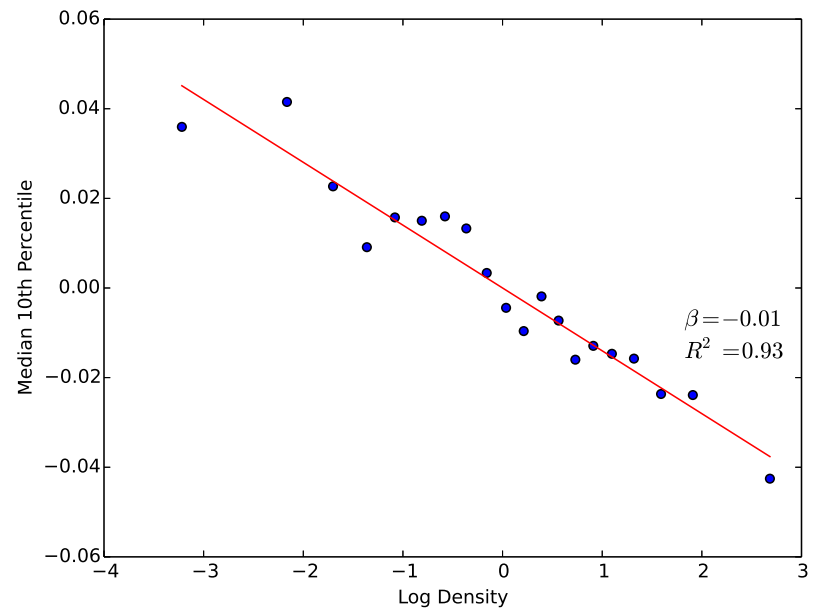

Figure 3.3: This figure represents the binned scatter plot of the relationship between population density and median 10th percentile of all the patents filed in a given CSD. Both variables are first regressed on state and year fixed effects as well as the total number of patents produced in that CSD.

\section{Fact 4: High-density is a predictor of a patent's impact}

The last fact that we describe is that densely populated areas have a strong advantage in producing high-impact patents. We show this by estimating a regression model similar to the one used to assess the effect of unconventionality on the probability of being a hit patent. More precisely, we estimate:

$$
\begin{aligned}
\operatorname{logit}\left(H I T_{\text {isct }}\right)= & \alpha+\delta_{t}+\delta_{c}+\delta_{\text {state }}+\beta \log \left(\text { density }_{\text {st }}\right)+\gamma \text { low } 10^{\text {th }} \text { perc }_{\text {icst }}+ \\
& +\theta \log \left(\text { densit }_{\text {st }}\right) \times \operatorname{low} 10^{\text {th }} \text { perc }_{\text {icst }}+\varepsilon_{\text {isct }}
\end{aligned}
$$

where $\beta$ is a measure of the absolute advantage of high-density areas in producing successful patents, whereas the coefficient of the interaction, $\theta$, is a measure of their comparative advantage in producing high impact unconventional innovations. Table 3.2 shows that both coefficients are positive and statistically significant. In particular, density has a positive effect on a patent's impact regardless of its conventionality, although the effect is stronger for unconventional innovations. This suggests that density is indeed a catalyzer of innovative activity. The geographical sorting documented in Fact 3 is probably the result of a balance between the interaction opportunities offered by high-density areas and the congestion costs that these areas entail. Conventional innovation benefits less from those opportunities and sorts itself outside urban centers. 


\begin{tabular}{c|ccccc} 
& low $10^{\text {th }}$ perc & low $10^{\text {th }}$ perc & low $10^{\text {th }}$ perc & low $10^{\text {th }}$ perc & low $10^{\text {th }}$ perc \\
\hline \hline Log population & $0.0087^{* * *}$ & $0.0069^{* * *}$ & $0.0064^{* * *}$ & $0.0040^{* * *}$ & $0.0033^{* *}$ \\
density & $(0.00165)$ & $(0.00157)$ & $(0.00167)$ & $(0.0014)$ & $(0.0016)$ \\
Log median & & $-0.0182^{* * *}$ & $-0.0270^{* * *}$ & $-0.0189^{* *}$ & $-0.0248^{* * *}$ \\
income & & $(0.00310)$ & $(0.00387)$ & $(0.0080)$ & $(0.0070)$ \\
\% High & & & $0.0352^{* * *}$ & 0.0275 & $0.0413^{* *}$ \\
education & & $(0.0125)$ & $(0.0184)$ & $(0.0165)$ \\
Gini & & & $0.1475^{* *}$ & $0.0998^{*}$ \\
& & & & $(0.0667)$ & $(0.0602)$ \\
Traded & & & & & $-0.0148^{* * *}$ \\
& & & & & yes \\
\hline State f.e. & yes & yes & yes & yes & yes \\
Year f.e. & yes & yes & yes & yes & yes \\
Class f.e. & yes & yes & yes & & 703,416 \\
\hline N. Obs & $1,058,992$ & $1,058,992$ & $1,058,992$ & $1,054,430$ & 0.008
\end{tabular}

Table 3.1: This table reports the marginal effects of a logit regression whose dependent variable is a dummy that takes value one if the 10th percentile of the c-score distribution of a given patent, produced in a given CSD is below the median with respect to other patents of a given class filed in the same year. Independent variables are added one at a time. Standard errors clustered at a state/year level are reported in parenthesis.

\subsection{Exploration of the Mechanism}

The empirical analysis of Section 3.1 shows that innovation tends to sort spatially according to its conventionality content. In this Section, we shed light on a mechanism that is likely to drive this pattern. Our hypothesis is that the interaction of individuals with different backgrounds can result into inventions that embed pieces of knowledge specific to their respective fields. Higher diversification multiplies the opportunities to share one's knowledge with people from fields that are increasingly far apart. Density, on its hand, facilitates this process further, by offering a wide range of events and possibilities for them to interact informally. Hence, high-density areas seem to be the natural environment where unconventional ideas can emerge. The findings of this Section provide strong support to the existence of localized knowledge spillovers, as conjectured by Lucas (1988). Furthermore, we provide a novel characterization of these spillovers by showing the existence of a so far neglected margin along which they manifest themselves, namely, the composition of the knowledge base upon which new ideas are built.

We perform two tests for our hypothesis. First, we show that places with a given technology mix are more likely to produce patents that display citations drawn from the same technology mix. We do this by running a set of logit regressions of the following form:

$$
\operatorname{logit}\left(\mathbb{1}_{\{X \wedge Y\}}\right)=\alpha+\beta_{X} s_{X}+\beta_{Y} s_{Y}+\beta_{X Y} s_{X} s_{Y}+\varepsilon
$$




\begin{tabular}{c|c} 
& Hit Probability \\
\hline \hline log population & $.0027^{* * *}$ \\
density & $(0.0003)$ \\
Low 10th & $0.0061^{* *}$ \\
percentile & $(0.0029)$ \\
Interaction & $0.0014^{* * *}$ \\
& $(0.0004)$ \\
\hline State f.e. & yes \\
Year f.e. & yes \\
Class f.e. & yes \\
\hline N. Obs & $1,058,975$ \\
pseudo $R^{2}$ & 0.0108
\end{tabular}

Table 3.2: This table reports the marginal effects of a logit regression whose dependent variable is a dummy variable that takes value one when the patent is a hit patent (i.e., in the top $5 \%$ of its class/year of the distribution of citations received). Standard errors clustered at a state/year level are reported in parenthesis.

where $\mathbb{1}_{\{X \wedge Y\}}$ is an indicator function that takes value one when a patent cites classes $X$ and $Y$ and $s_{Z}$ is the share of patents of class $Z \in\{X, Y\}$ produced in CSD $s$. We run on regression of this type for each class pair such that $X \neq Y$ (for a total of $107 \times 106$ regressions), and we record the sign of $\beta_{X Y}$. When we observe $\beta_{X Y}>0$ means that it is more likely to observe patents that cite classes $X$ and $Y$ together in places with a high share of patents of class $X$ and a high share of patents of class $Y$. Figure 3.4 is a graphical representation of our results. Every pixel in the matrix is colored according to the sign of $\beta_{X Y}$, blue if negative, red if positive. From a first inspection one can notice that there is a clear tendency towards red in the picture. In fact, $75.24 \%$ of our regressions give a positive estimate of $\beta_{X Y}$.

Of course, this exercise only provides suggestive evidence. It might be that a firm that wants to produce an innovation with uncommon contents, say computerized shoes, locates itself in a place where there are a lot of computer and shoe firms. In order to address this concern, we perform a difference-in-difference analysis as follows. First, we take all the firms that filed a patent in 2000 in every CSD as our sample population. Second, for each patent class, c, we compute the share of citations that it receives in a given CSD/year from patents of classes different from $c$. This is our left hand side variable, $S_{c s t}$. The overall mean of this variable is 0.0043 . Since by construction the average share of citations received by any given class is $\frac{1}{107}=0.0093$, the value of 0.0043 implies that more than half of the citations from a given class are towards patents of its own class. Third, we construct the shocks at a class/CSD/year level. We define a shock as the arrival of a new firm of a given class in a given CSD in a given year. Every firm is associated to a class based on their technology output. In particular, we consider all the patents filed by a firm over the whole period and we take the class that recurs more often 


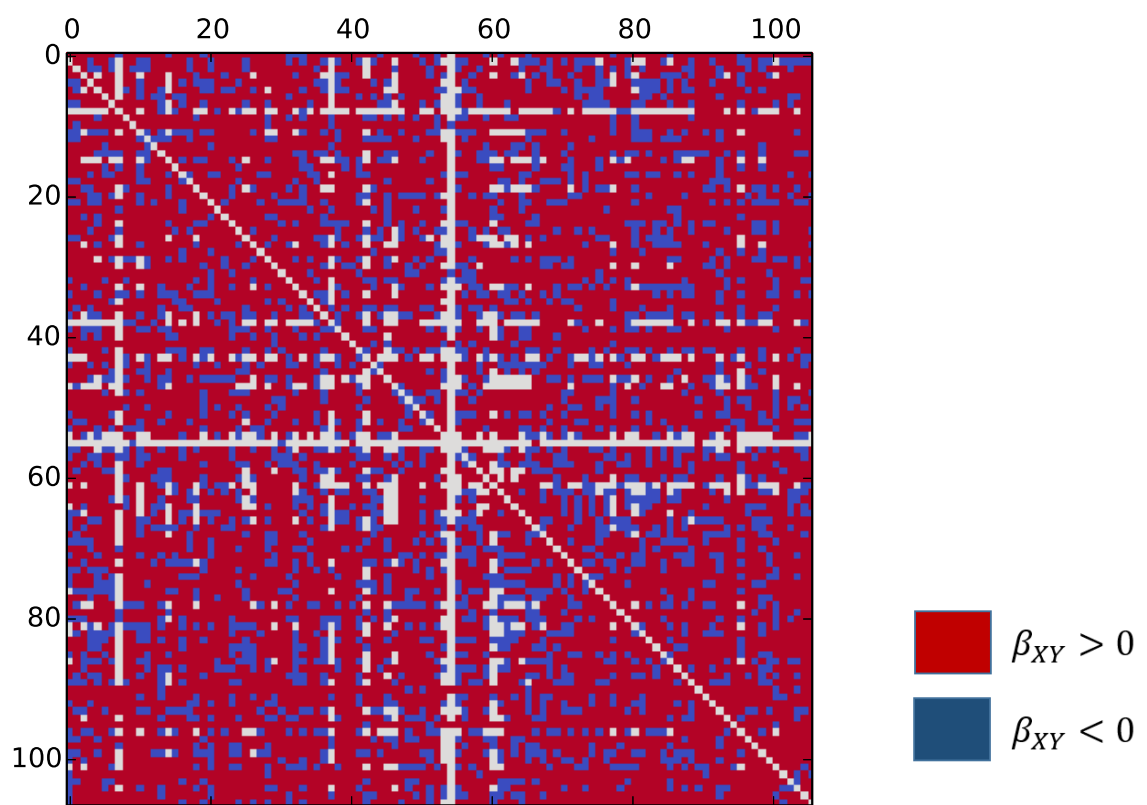

Figure 3.4: The figure plots the coefficients of a logit regression of an indicator variable that takes value one when a given patent cites both class $X$ and $Y$ on the share of patents of class $X$ produced in the patent's CSD, the share of patents of class $Y$ produced in the patent's CSD and their interaction. Red (blue) pixels denote a positive (negative) coefficient of the interaction term.

in the data. To proxy for the arrival of a new firm, we use the first year in which a firm not in the initial population files a patent after 2001. We consider this arrival as exogenous from the point of view of the 2000 population. Finally, we run a difference-in-difference regression to estimate the impact of such a shock on $S_{c s t}$. Formally, we estimate:

$$
S_{c s t}=\alpha+\delta_{t}+\delta_{c s}+\beta A_{c s t}
$$

where $\delta_{t}$ are time fixed effects, $\delta_{c s}$ are class/CSD fixed effects and $A_{c s t}$ is a dummy variable that takes value 1 the year after the arrival of a firm of class $c$ in CSD $s$ and remains equal to 1 thereafter, $\beta$ is the diff-in-diff estimator. Column 1 of Table 3.3 reports the estimation of the empirical model. The diff-in-diff regression delivers an estimated coefficient that is positive, statistically significant, as well as relevant in magnitude (recall that the mean of the left hand side variable is 0.0043 ).

We perform four robustness checks. First, in column 2, we add to our baseline specification a time/class trend. The estimate of $\beta$ is now somewhat smaller but always significant and relevant in magnitude. Second, we weight the shock so that it takes into consideration both 


\begin{tabular}{c|ccccc} 
& share $_{\text {cit }}$ & share $_{\text {cit }}$ & share $_{\text {cit }}$ & share $_{\text {cit }}$ & share $_{\text {cit }}$ \\
\hline \hline Arrival of & $0.0012^{* * *}$ & $0.0004^{* *}$ & $0.0050^{* * *}$ & $0.0014^{* * *}$ & $.0017^{* * *}$ \\
new firm & $(0.0002)$ & $(0.0002)$ & $(0.0011)$ & $(0.0002)$ & $(0.0003)$ \\
\hline Class/CSD f.e. & yes & yes & yes & yes & yes \\
Year f.e. & yes & yes & yes & yes & yes \\
Trend & no & yes & no & no & no \\
Weighted shock & no & no & yes & no & no \\
Shock arrival year & 2001 & 2001 & 2001 & 2002 & 2005 \\
\hline N. Obs & 682,116 & 682,116 & 682,116 & 682,116 & 682,116 \\
$R^{2}$ & 0.0217 & 0.0668 & 0.0352 & 0.0200 & 0.0109
\end{tabular}

Table 3.3: This table reports the coefficients of a logit regression of the share of citations received by patent class $c$ from patents of classes other than $c$ in a given CSD at a given time on time and class/CSD fixed effects and a dummy that indicates the arrival of a new firm of class $c$ in that CSD. Column 1 reports the estimates of the baseline diff-in-diff specification. Column 2 the estimates obtained after adding time trends to the baseline specification. Column 3 the estimates obtained with a shock weighted according to the size and number of the incoming firms. Standard errors clustered at a state/year level are reported in parenthesis.

the size and number of the incoming firms. In our baseline exercise we adopted a conservative stance by assuming that every incoming firm has potentially the same impact on the innovation market regardless of its size, and we did not consider subsequent arrivals (see Appendix for more details). Column 3 shows that the coefficient estimated with the weighted shock is consistent with the previous exercises, although the magnitudes are not directly comparable. Third, to build our shock, we only consider firms whose first patent in a certain CSD is filed in later years. Column 4 and 5 report the estimates obtained when we consider 2002 and 2005 as arrival years, respectively. The estimates are virtually unchanged by this new specification.

Finally, we run a placebo test by adding to the regression leads and lags of the shock. The new specification has the following form:

$$
S_{c s t}=\alpha+\delta_{t}+\delta_{c s}+\sum_{j=-2}^{5} \beta_{j} A_{c s t}^{t-j}
$$

where $A_{c s t}^{t-j}$ is an indicator variable that takes value one if at time $t-j$ there is a shock in class $c$ and CSD $s$. Note that the last shock is equal to 1 for the whole future and therefore captures the cumulative effect from $t+5$ on. Figure 3.5 plots the values of the $\beta_{j}$ 's and their $90 \%$ confidence intervals. The estimates are never statistically significant before the shock. However, they are always positive and statistically different from 0 from the time of the shock on. Also, as one would expect, the effect is increasing over time. 


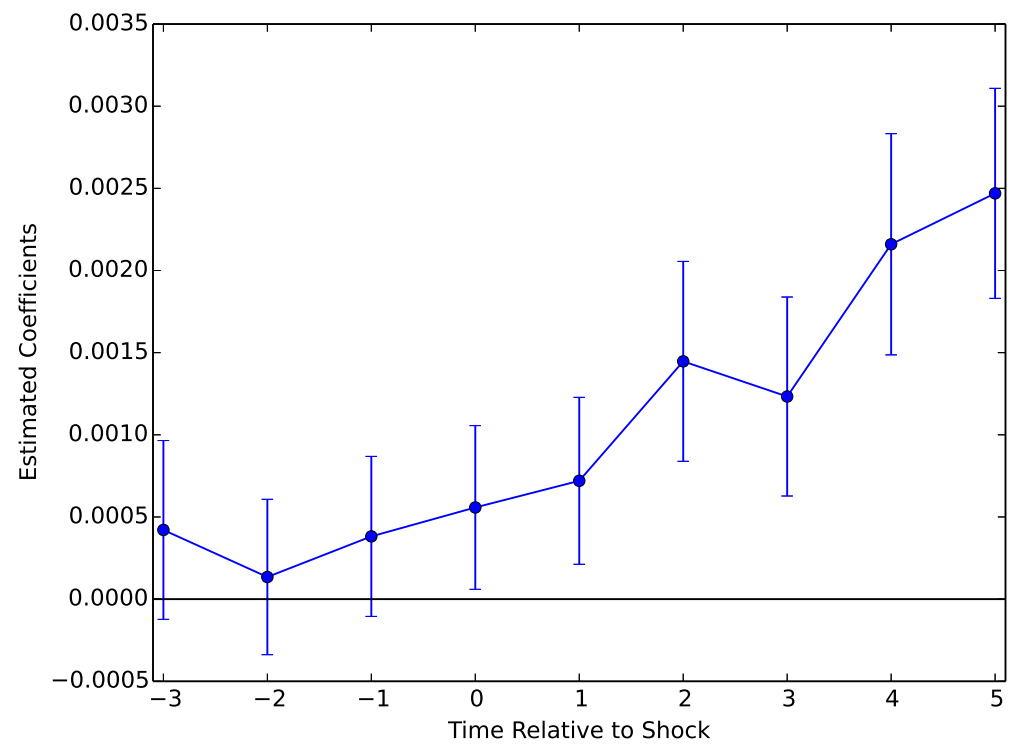

Figure 3.5: This figure plots the coefficients of a logit regression of the share of citations received by patent class $c$ from patents of classes other than $c$ in a given CSD at a given time on time and class/CSD fixed effects and the leads and the lags of a dummy that indicates the arrival of a new firm of class $c$ in that CSD. Negative numbers on the $\mathrm{x}$-axis represent leads of the shocks, while positive numbers lags. Bars indicate $90 \%$ confidence intervals.

\section{Model}

The existence of cross-field local spillovers suggests that economic geography not only affects how much innovation an economy is able to produce, but also its composition. From an economic point of view, conventional and unconventional innovation can have markedly different implications. While the former is crucial to the improvement of existing products and the optimization of existing processes, the latter can be the foundation for creating new products or disruptively enter a market by displacing existing producers. This is reflected in the significantly higher impact of unconventional patents in terms of citations received.

In this section, we explore the interaction between economic geography and the composition of innovation in a fully-specified, endogenous growth model of a spatial economy in which the heterogeneous nature of innovation is explicitly taken into account. In its positive implications, the model rationalizes the observed pattern of geographical sorting of innovation activity by showing that low-density, specialized locations can coexist with high-density, diversified cities.

We start this section by describing the setting of the model economy. We will assume a closed economy with a representative consumer and a homogeneous final good, produced through a Cobb-Douglas aggregator of a continuum of varieties. As in Peters (2013) and Hanley (2014) we assume a leader-follower structure with limit pricing. This generates heterogeneous markups 
and induces a static misallocation of labor across intermediate producers. Unconventional innovation results in creative destruction: the incumbent leader is replaced by a new one, and the technological lead is reset. Conventional innovation allows the leader to increase its technological lead. The locational choice of innovators determines their opportunities of interaction, and pins down not only the intensity of innovation, but also, and crucially, its composition. This in turn affects the static and dynamic properties of the economy.

We will then calibrate the model using a combination of aggregate data and specific moments derived from our patent data and use the quantitative results to study the welfare implications of place-based policies. Our calibration reveals that the optimal policy subsidizes unconventional innovation in cities, sacrifices growth and congestion costs and reduces static market distortion. We then show that this type of policies becomes even more necessary if an increase in the supply of conventional innovation, like the one observed in the last decade from emerging economies, hits the innovation landscape.

\subsection{Setting}

Consider a continuous time environment in which a representative consumer has access to a homogeneous final good which is valued according to:

$$
U_{t}=\int_{t}^{\infty} e^{-\rho(s-t)} \log \left(c_{t}\right) d s .
$$

The final good $Y_{t}$ is produced by a competitive firm that aggregates a continuum of intermediate varieties in the interval $[0,1]$ through a Cobb-Douglas production function:

$$
\log \left(Y_{t}\right)=\int_{0}^{1} \log \left(y_{i t}\right) d i .
$$

The final good producer takes prices of the intermediate varieties as given. Normalizing the price of the final good to $P_{t}=1$, profit maximization implies:

$$
Y_{t}=p_{i t} y_{i t}
$$

The form of the demand function of each variety reveals that the revenues of intermediate producers only depend on aggregate output. Hence, intermediate varieties are only produced by the most efficient intermediate firm that charges the highest possible price in order to minimize total production costs. 


\section{Intermediate Producers}

The most efficient producer (the "leader", denoted by $L$ ) of each variety $i$ employs unskilled labor $l_{i t}$ at wage $w_{t}$ to produce output $y_{i t}$ according to a linear production function:

$$
y_{i t}=a_{i t}^{L} l_{i t}
$$

where $a_{i t}^{L}$ denotes the labor productivity of the leader. We follow the recent literature on Schumpeterian growth with limit pricing ${ }^{12}$ and assume that each intermediate variety $i$ at time $t$ can be identified by a leader-follower distance $\Delta_{i t} \geq 0$, such that:

$$
a_{i t}^{L}=\left(1+\lambda_{0}\right)\left(1+\lambda_{1}\right)^{\Delta_{i t}} a_{i t}^{F}
$$

where $a_{i t}^{F}$ is the labor productivity of the second most efficient producer (the "follower"). In the expression above, $\left(1+\lambda_{0}\right)$ is the jump factor by which the previous leader's productivity is improved upon losing leadership, while $\left(1+\lambda_{1}\right)$ is the jump factor by which the current leader's productivity is improved upon receiving a conventional innovation. The leader maximizes current profits by setting a price that is just below the follower's marginal cost:

$$
p_{i t}=\frac{w_{t}}{a_{i t}^{F}}
$$

which results in a markup over its own marginal cost equal to:

$$
\mu_{i t}=\mu\left(\Delta_{i t}\right)=\frac{a_{i t}^{L}}{a_{i t}^{F}}=\left(1+\lambda_{0}\right)\left(1+\lambda_{1}\right)^{\Delta_{i t}}
$$

Profits can be written as:

$$
\pi_{i t}=\pi_{t}\left(\Delta_{i t}\right)=p_{i t} y_{i t}-\frac{w_{t}}{a_{i t}^{L}} y_{i t}=Y_{t}\left(1-\mu_{i t}\right)
$$

It is easy to see that, given aggregate output $Y_{t}$, profits are an increasing and concave function of $\Delta_{i t}$ that converges to $Y_{t}$ as $\Delta_{i t}$ grows to infinity. Substituting the optimal intermediate firm's decisions into (3), the expression for aggregate output becomes:

$$
\log \left(Y_{t}\right)=\log \left(N^{F}\right)+\int_{0}^{1} \log \left(a_{i t}^{L}\right) d i+\int_{0}^{1} \log \left(\mu_{i t}^{-1}\right) d i-\log \left(E\left[[\mu(\Delta)]^{-1}\right]\right)
$$

where $N^{F}=\int_{0}^{1} l_{i} d i$ is the total amount of unskilled labor employed by intermediate producers.

Expression (6) decomposes aggregate output into an aggregate "input" term , log $\left(N^{F}\right)$, an

\footnotetext{
${ }^{12}$ See Peters (2013) and Hanley (2014).
} 
"aggregate technology" term, $\int_{0}^{1} \log \left(a_{i t}^{L}\right) d i$, and a "static distortion" term, $\int_{0}^{1} \log \left(\mu_{i t}^{-1}\right) d i-$ $\log \left(E\left[\mu_{i t}^{-1}\right]\right)$, which reflects the misallocation of labor resulting from heterogeneous markups. To see why the third term represents a static loss from resource misallocation, note that, by Jensen's inequality, it is always weakly negative, and is equal to zero only if almost every intermediate producer charges the same markup.

\section{The Leader}

Consider the current leader in product line $i$ who currently holds an advantage on the follower of size $\Delta_{i t}$. She is subject to two types of idiosyncratic events, a conventional innovation that improves her productivity, and a creative destruction shock that pushes the leader out of the market. In this section, we take the frequency of these shocks as exogenous and endogenize it in the next one.

First, with Poisson rate $\psi_{t}>0$, the leader is contacted by an innovator who offers him a conventional technological improvement that increases the productivity by a factor $\left(1+\lambda_{1}\right)$. We assume that conventional innovators always find it optimal to contact the current leader. As a result, the productivity of followers is stagnant. Patent protection of previous underlying technologies prevents the innovator from making any alternative use of the idea. Denoting by $V_{t}\left(\Delta_{i t}\right)$ the value of the leader at $\Delta_{i t}$, the resulting surplus is:

$$
S_{t}\left(\Delta_{i t}\right)=V_{t}\left(\Delta_{i t}+1\right)-V_{t}\left(\Delta_{i t}\right)
$$

If a conventional innovator contacts the leader, a bargaining process begins and a fraction $b \in(0,1)$ of the resulting surplus is paid by the firm to the innovator. The incremental innovator receives a payment equal to:

$$
\beta_{t}\left(\Delta_{i t}\right)=b S_{t}\left(\Delta_{i t}\right)
$$

Second, with Poisson rate $\zeta_{t}>0$, an inventor develops an unconventional innovation that improves the productivity of the current leader by a factor $\left(1+\lambda_{0}\right)$. The key difference between conventional and unconventional ideas is that, while the former rely on underlying technologies for which the leader enjoys patent protection, the latter can be implemented without infringing the leader's intellectual property. The inventor can set up a new firm and becomes the new leader, while the previous leader becomes the current follower. This event resets the technological lead in product line $i$ to $\Delta_{i t}=0$.

The value function for a leader with technological lead $\Delta$ is therefore:

$$
\left(r_{t}+\psi_{t}+\zeta_{t}\right) V_{t}(\Delta)=\pi_{t}(\Delta)+\psi_{t}\left[V_{t}(\Delta+1)-\beta_{t}(\Delta)\right]
$$


In what follows, whenever the time subscript is dropped, we refer to the corresponding variable in balanced growth path (BGP). For all non-stationary variables, we impose stationarity by dividing the corresponding variable by $Y_{t}{ }^{13}$ The stationary value function reads:

$$
(\rho+\psi+\zeta) V(\Delta)=\pi(\Delta)+\psi[V(\Delta+1)-\beta(\Delta)] .
$$

Equation (7) makes use of the fact that, along the balanced growth path, the interest rate is constant and equal to:

$$
r=\rho+g .
$$

The analytical expression for the stationary value function are found by guessing and verifying the following form:

$$
V(\Delta)=A-B[\mu(\Delta)]^{-1} .
$$

Matching coefficients for $A$ and $B$ delivers:

$$
A=\frac{1}{\rho+\zeta} \quad B=\frac{\left(1+\lambda_{1}\right)}{\left(1+\lambda_{1}\right)[\rho+\zeta]+\psi(1-b) \lambda_{1}} .
$$

This gives the value of a conventional innovation to a product line with technological lead $\Delta$ :

$$
\begin{aligned}
\beta(\Delta) & =b B\left\{[\mu(\Delta)]^{-1}-[\mu(\Delta+1)]^{-1}\right\} \\
& =\frac{b B \lambda_{1}}{\left(1+\lambda_{1}\right)}[\mu(\Delta)]^{-1}
\end{aligned}
$$

It is easy to see that $\beta(\Delta)$ is decreasing in $\Delta$.

\section{Stationary Distributions and Balanced Growth Path}

Let $\nu(\Delta)$ denote the stationary mass of product lines with technological lead equal to $\Delta$. It can be computed as the solution of the following recursive system:

$$
\begin{cases}\zeta[1-\nu(\Delta)]=\psi \nu(\Delta) & \Delta=0 \\ \psi v(\Delta-1)=(\zeta+\psi) v(\Delta) & \Delta \geq 1\end{cases}
$$

which has the following solution:

$$
\nu(\Delta)=\frac{\zeta}{\zeta+\psi}\left(\frac{\psi}{\zeta+\psi}\right)^{\Delta} .
$$

\footnotetext{
${ }^{13}$ For example, we let $V(\Delta)=\frac{V_{t}(\Delta)}{Y_{t}}$ in BGP. Also, by definition, $Y=1$.
} 
This reveals that the stationary distribution of technological leads is geometric with an intercept that negatively depends on the ratio of conventional and unconventional innovation, $\frac{\psi}{\zeta}$. We can also compute the following objects that will be useful is later derivations: ${ }^{14}$

$$
\begin{aligned}
E[\Delta] & =\sum_{\Delta=0}^{\infty} \Delta \nu(\Delta)=\frac{\psi}{\zeta} \\
E[\mu(\Delta)] & =\frac{\zeta\left(1+\lambda_{0}\right)}{\zeta-\psi \lambda_{1}} \\
E\left[[\mu(\Delta)]^{-1}\right] & =\frac{\zeta\left(1+\lambda_{1}\right)}{\left(1+\lambda_{0}\right)\left[\left(1+\lambda_{1}\right) \zeta+\lambda_{1} \psi\right]} .
\end{aligned}
$$

From (6), we can see that along the BGP, the growth rate of output is simply given by the average growth rate of productivity of the intermediate varieties:

$$
g=\int_{0}^{1} \frac{\dot{a}_{i}^{L}}{a_{i}^{L}} d i=\lambda_{0} \zeta+\lambda_{1} \psi
$$

\section{Cities and Innovation}

Up to this point, we treated the aggregate rates of innovation, $\zeta$ and $\psi$, as exogenous. In order to understand the spatial dimension of the innovation process, we endogenize them by assuming that innovation takes place in a system of cities that we now describe.

There are $K$ cities with a downtown neighborhood of area 1 and vast outskirts. Since the main intuition of the model goes through with three cities, for most of the analysis we will assume $K=3$, but the model can be easily generalized to the case $K>3$. Rural areas between cities host physical production activities. The world is populated by a mass of unskilled workers normalized to $K$ and a mass of skilled workers equal to $X=x K$, where $x \in(0,1)$.

Unskilled workers live in the outskirts or in the rural area, where congestion costs are zero, and inelastically supply 1 unit of labor to either intermediate producers or to the housing/nontradable sector. We normalize the total supply of unskilled labor to $K$ (namely, there is a mass one of workers for each potential location). Letting $N^{H}$ denote the mass of unskilled workers who choose to work for the housing sector (and recalling that $N^{F}$ denotes the mass of unskilled labor working for intermediate producers), we have:

$$
N^{H}+N^{F}=K \text {. }
$$

Skilled workers live in the downtown area and are exclusively devoted to the production of ideas. Each innovator belongs to a given technology class $\tau \in \mathcal{T}$ which represents his personal

\footnotetext{
${ }^{14}$ These expressions are derived under the assumption, to be verified later, that $\zeta>\psi \lambda_{1}$
} 


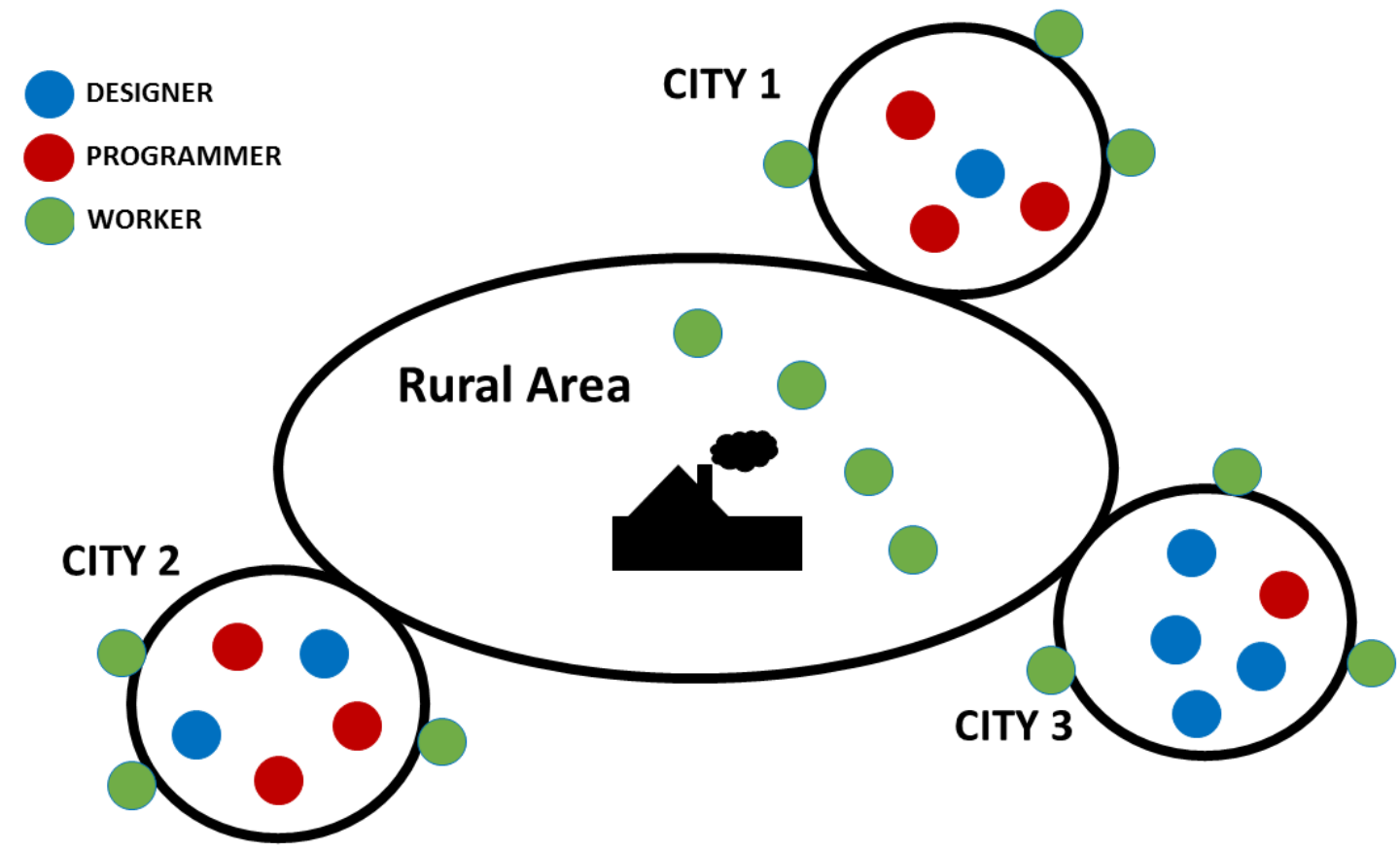

Figure 4.1: Spatial economy: Illustration. Innovators from background $\tau_{1}$ and $\tau_{2}$ (for example, designers and programmers) sort themselves into the downtown areas of cities. Unskilled labor lives in the outskirts of cities, while production takes place in rural areas between cities.

knowledge background. For simplicity, in what follows, we assume $\mathcal{T}$ only contains three technology classes, $\mathcal{T}=\left\{\tau_{1}, \tau_{2}, \tau_{F}\right\}$, where $\tau_{1}$ and $\tau_{2}$ are the knowledge backgrounds of the innovators, whereas $\tau_{F}$ is the technology class of the innovation output. Production of new knowledge in $\tau_{F}$ requires combining previous knowledge contained in $\tau_{F}$ with other ideas from $\tau_{1}$ and $\tau_{2}$. We further assume that the mass of innovators from background $\tau_{1}$ is equal to the mass of innovators from background $\tau_{2}$, that is:

$$
X^{\tau_{1}}=X^{\tau_{2}}=\frac{X}{2} .
$$

Figure 4.1 provides a graphical illustration of the structure of the spatial economy.

An innovator of technology class $\tau$ living in city $k$ receives ideas with Poisson rate $d\left(X_{k}^{\tau}\right)$. Following the empirical literature on localized knowledge spillovers, we assume $d(\cdot)$ is an increasing, iso-elastic function:

$$
d\left(X_{k}^{\tau}\right)=\alpha_{0}\left(X_{k}^{\tau}\right)^{\alpha_{1}} .
$$

The implementation of each idea requires the combination of two innovators (the first supplying the idea, the second supplying operative support), whose backgrounds determine the tail conventionality of the innovation. For simplicity of notation, we assume the entire surplus of the innovation goes to the innovator with the initial idea. This setting is equivalent to assuming 
that the first and the second innovator split the resulting surplus in fixed shares.

An innovation generated through an idea of class $\tau_{h}$ complemented with the support of an innovator from class $\tau_{j}$ produce an innovation with tail conventionality $c\left(\tau_{h}, \tau_{j}\right)$. The main friction we introduce is the following. An innovator of class $\tau_{h}$ wishing to work with another innovator of the same class can do it through his network of formal interactions (e.g. the workplace) without being involved in any form of search activity. An innovator of class $\tau_{h}$ wishing to implement his idea with an innovator of background $\tau_{j}$, with $h \neq j$, must do it through informal interactions and will be able to find a fellow innovator of class $\tau_{j}$ with probability:

$$
P\left(\tau_{h} \text { meets } \tau_{j}\right)=z X_{k}^{\tau_{j}}
$$

with $z \in(0,1)$. Expression (11) can be directly interpreted as reflecting spatial search frictions on the side of $\tau_{h}$. Since the area of the city is normalized to one, $X_{k}^{\tau_{j}}$ is the probability that a point in the city is occupied by an innovator of class $\tau_{j}$, while $z$ is an exogenous parameter introduced for calibration purposes. If search is unsuccessful, the idea is lost and cannot be recycled for any alternative use. Expression (11) is at the heart of the mechanism that favors diversification in highly densely populated cities.

\section{Conventional Innovation and Creative Destruction}

If the tail conventionality of the combination is below one, i.e. $c\left(\tau_{h}, \tau_{i}\right)<1$, the idea can be used to gain leadership over a randomly selected product line $i \in[0,1]$. This corresponds to a creative destruction shock and generates a monetary value equal to $V(0) .{ }^{15}$ If instead the tail conventionality is above one, i.e. $c\left(\tau_{h}, \tau_{j}\right)>1$, the idea can only be used to improve existing technologies in a randomly selected product line $i \in[0,1]$ that are protected by patents owned by the leader. In this case, the leader is contacted and the innovator gets a monetary payment according to (8).

Every new invention receives a patent that cites the two backgrounds $\left(\tau_{h}\right.$ and $\tau_{j}$, or "tail citations") as well as several other patents of class $\tau_{F}$. In particular, we assume that every conventional patent cites all the inventions in the product line it builds on (i.e. starting from the unconventional invention that awarded the variety to the current leader), while every unconventional patent cites all the inventions in the same product line since the last creative destruction event (i.e. starting from the unconventional invention that awarded the variety to the previous leader).

The following proposition characterizes tail conventionality along a symmetric BGP (a growth path in which the contribution to aggregate innovation is identical for the two technology classes).

\footnotetext{
${ }^{15}$ We assume innovators discount the future with the representative consumer's marginal utility, $\rho+g=r$, so that their intertemporal preferences are aligned with the ones of the intermediate firms.
} 
Proposition 1. Assume $\mathcal{T}=\left\{\tau_{1}, \tau_{2}, \tau_{F}\right\}$. Along a symmetric balanced growth path in which $\psi>\zeta$, then $c\left(\tau_{h}, \tau_{j}\right)>1$ whenever $h=j$ and $c\left(\tau_{h}, \tau_{j}\right)<1$ whenever $h \neq j$.

Proof. See Appendix.

Proposition 1 suggests that an equilibrium of this economy can be computed by guessing that $\psi>\zeta$ and solving for the optimal innovation choice, under the assumption that different knowledge inputs generate unconventional combinations, whereas same-class inputs generate conventional ones, and finally verifying that the condition $\psi>\zeta$ is satisfied (we will assume it is actually the case in the rest of the analysis and then show the condition actually holds when we present our calibration). The optimal choice of an innovator of class $\tau_{h}$ in city $k$ is to implement the idea through informal interaction if and only if: ${ }^{16}$

$$
\mathcal{D}_{k}^{\tau_{i}}=\frac{z\left[X_{k}^{\tau_{j}} V(0)+X_{k}^{\tau_{h}} E[\beta(\Delta)]\right]}{E_{\Delta}[\beta(\Delta)]} \geq 1
$$

where $E_{\Delta}[\beta(\Delta)]$ is the expected monetary payment of a conventional innovation, that is:

$$
E_{\Delta}[\beta(\Delta)]=\frac{b B \lambda_{1}}{\left(1+\lambda_{1}\right)} E\left[[\mu(\Delta)]^{-1}\right] .
$$

The choice between conventional and unconventional innovation depends both on the mass of innovators of different background and on the relative monetary value of the two. The latter can be written as:

$$
\mathcal{V}(\psi, \zeta)=\frac{V(0)}{E_{\Delta}[\beta(\Delta)]}=\frac{\left\{\left(1+\lambda_{0}\right) \lambda_{1} \psi(1-b)+\lambda_{0}\left(1+\lambda_{1}\right)[\rho+\zeta]\right\}\left\{\left(1+\lambda_{1}\right)+\frac{\psi}{\zeta} \lambda_{1}\right\}}{[\rho+\zeta] b \lambda_{1}\left(1+\lambda_{1}\right)} .
$$

It is easy to verify that $\mathcal{V}(\psi, \zeta)$ is increasing in $\psi$ and decreasing in $\zeta$. This reflects a key complementarity between conventional and unconventional ideas. An increase in the supply of conventional innovation both increases the returns to gaining the leadership in a product line, pushing towards higher unconventionality, and decreases the returns to incremental improvements due to the concavity of $V(\Delta)$.

\section{Housing and Locational Choice}

Competitive city planners in downtown neighborhoods build houses (or supply non-tradable goods) by hiring unskilled labor. The amount of labor needed to produce $H_{k}$ houses in city $k$ is:

$$
N_{k}^{H}=f\left(H_{k}\right)
$$

\footnotetext{
${ }^{16}$ We assume that the innovator always resolves indifference in favor of informal interactions, but this case will not be considered in the analysis of the equilibrium.
} 
where $f(\cdot) \geq 0$ is an increasing and convex function satisfying:

$$
\lim _{H_{k} \rightarrow 1^{-}} f^{\prime}\left(H_{k}\right)=+\infty
$$

Every skilled worker consumes one unit of housing at every point in time and pays the market rent. In a city of population $X_{k}$, this is equal to:

$$
r_{k}=w f^{\prime}\left(X_{k}\right)
$$

The utility of a skilled worker from class $\tau_{1}$ living in a city $k$ populated by $X_{k}=X_{k}^{\tau_{1}}+X_{k}^{\tau_{2}}$ people can be written as (the one for innovators of class $\tau_{2}$ is specular):

$$
W_{k}^{\tau_{1}}= \begin{cases}-r_{k}+d\left(X_{k}^{\tau_{1}}\right) E_{\Delta}[\beta(\Delta)] & \mathcal{D}_{k}^{\tau_{1}}<1 \\ -r_{k}+d\left(X_{k}^{\tau_{1}}\right) z\left[X_{k}^{\tau_{2}} V(0)+X_{k}^{\tau_{1}} E_{\Delta}[\beta(\Delta)]\right] & \mathcal{D}_{k}^{\tau_{1}} \geq 1\end{cases}
$$

\section{Market Clearing and Spatial Equilibrium}

Unskilled labor that is not used in the housing/non-tradable sector is employed in the production of intermediate varieties. Aggregating the labor demand schedule of intermediate producers, one obtains:

$$
N^{F}=\frac{Y}{w} E\left[[\mu(\Delta)]^{-1}\right]=\frac{\zeta\left(1+\lambda_{1}\right)}{w\left(1+\lambda_{0}\right)\left[\left(1+\lambda_{1}\right) \zeta+\lambda_{1} \psi\right]}
$$

which, together with (10) and (14), pins down the market wage $w$.

Aggregate innovation rates are pinned down by innovators' locational choices and their decisions to implement ideas through formal or informal social interactions. In particular:

$$
\begin{aligned}
\psi & =\sum_{k=1}^{K} \sum_{\tau \in \mathcal{T}} d\left(X_{k}^{\tau}\right)\left\{X_{k}^{\tau} \mathbb{1}_{\left\{\mathcal{D}_{k}^{\tau}<1\right\}}+z\left(X_{k}^{\tau}\right)^{2} \mathbb{1}_{\left\{\mathcal{D}_{k}^{\tau}<1\right\}}\right\} \\
\zeta & =\sum_{k=1}^{K} \sum_{\tau \in \mathcal{T}} d\left(X_{k}^{\tau}\right) z X_{k}^{\tau} X_{k}^{-\tau} \mathbb{1}_{\left\{\mathcal{D}_{k}^{\tau} \geq 1\right\}}
\end{aligned}
$$

We finally have all the ingredients to define a spatial equilibrium in this economy. The key novel feature of this spatial setting is that the market price of the two types of innovation is endogenous and depends on the spatial organization of innovative activity.

Definition 1. A Symmetric BGP Spatial Equilibrium with Perfect Sorting is a collection of locational choices $\left\{X_{k}^{\tau_{1}}, X_{k}^{\tau_{2}}\right\}_{k=1}^{K}$ and innovation decisions $\left\{\mathcal{D}_{k}^{\tau_{1}}, \mathcal{D}_{k}^{\tau_{2}}\right\}_{k=1}^{K}$ such that:

(1) Whenever $X_{k}^{\tau}>0, k \in \arg \max \left\{W_{k}^{\tau}\right\}_{k=1}^{K}$

(2) The contribution to the implied rates of aggregate innovation is the same across the two 
classes, i.e.:

$$
\begin{gathered}
\sum_{k=1}^{K} d\left(X_{k}^{\tau_{1}}\right)\left\{X_{k}^{\tau_{1}} \mathbb{1}_{\left\{\mathcal{D}_{k}^{\tau_{1}}<1\right\}}+z\left(X_{k}^{\tau_{1}}\right)^{2} \mathbb{1}_{\left\{\mathcal{D}_{k}^{\left.\tau_{1} \geq 1\right\}}\right\}}=\sum_{k=1}^{K} d\left(X_{k}^{\tau_{2}}\right)\left\{X_{k}^{\tau_{2}} \mathbb{1}_{\left\{\mathcal{D}_{k}^{\tau_{2}}<1\right\}}+z\left(X_{k}^{\tau_{2}}\right)^{2} \mathbb{1}_{\left\{\mathcal{D}_{k}^{\tau_{2}} \geq 1\right\}}\right\}\right. \\
\sum_{k=1}^{K} d\left(X_{k}^{\tau_{1}}\right) z X_{k}^{\tau_{1}} X_{k}^{\tau_{2}} \mathbb{1}_{\left\{\mathcal{D}_{k}^{\tau_{1}} \geq 1\right\}}=\sum_{k=1}^{K} d\left(X_{k}^{\tau_{2}}\right) z X_{k}^{\tau_{2}} X_{k}^{\tau_{1}} \mathbb{1}_{\left\{\mathcal{D}_{k}^{\tau_{2}} \geq 1\right\}}
\end{gathered}
$$

(3) Every location $k$ is either fully specialized (i.e. there exists $\tau$ such that $X_{k}^{\tau}=X_{k}$ ) or has a representative share of all technology classes $\left(\frac{X_{k}^{\tau}}{X_{k}}=\frac{X^{\tau}}{X}\right.$ for every $\left.\tau \in \mathcal{T}\right)$.

(4) All non-stationary quantities grow at the same rate $g$, defined by:

$$
g=\lambda_{0} \zeta+\lambda_{1} \psi
$$

\section{Equilibria with Three Cities}

As it is common in most spatial equilibrium models, there can be several equilibria depending on parameter values (in particular, the degree of spatial complementarities). A complete characterization of symmetric equilibria would not be feasible in this setting. We focus on the case $K=3$ and purposely rule out all the balanced growth paths in which all cities are equally representative of each technology background. As in Duranton and Puga (2001), we restrict our attention to symmetric equilibria that display a mix of fully diversified and fully specialized cities. This class of equilibria displays a spatial sorting of technology classes like the one shown in Figure 4.2 .

The equilibrium shows the emergence of two classes of cities. A densely-populated, diversified city (City 1) and two sparse and specialized cities (City 2 and City 3). Innovators in specialized cities enjoy lower congestion costs and might receive more or less class-specific spillovers compared to the diversified city, depending on the mass of same-class neighbors. In what follows, we denote by $k^{\tau_{h}}$ the city specialized in $\tau_{h}$ and $k^{d}$ the diversified city and we let $\eta$ be the share of innovators living in the diversified city. Incorporating symmetry, population in the two types of cities can be written as:

$$
\begin{aligned}
X_{k^{d}} & =\eta X \\
X_{k^{\tau_{1}}} & =\frac{(1-\eta) X}{2}
\end{aligned}
$$




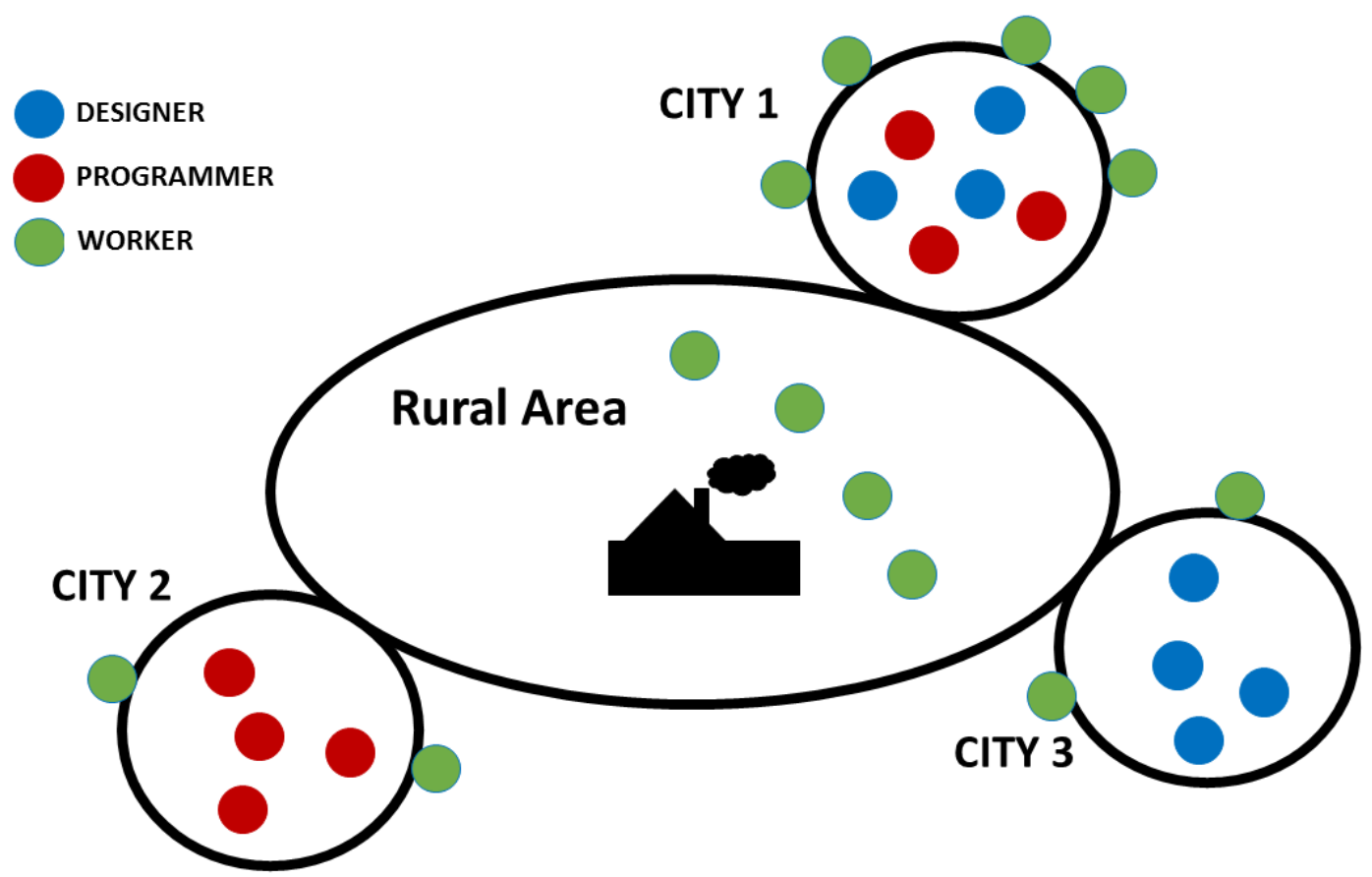

Figure 4.2: Spatial economy: Equilibrium. City 1 is dense and diversified. City 2 and 3 are scattered and specialized.

Aggregate innovation rates are given by:

$$
\begin{aligned}
\zeta & =2 z \alpha_{0}(\eta X)^{2+\alpha_{1}} \\
\psi & =\zeta+2 \alpha_{0}\left[\frac{(1-\eta) X}{2}\right]^{1+\alpha_{1}}
\end{aligned}
$$

which also implies that the assumption of Proposition $1, \psi>\zeta$, is indeed satisfied in this equilibrium as long as $\eta \neq 1$. This gives us a simple expression for the degree of incrementalism in the economy:

$$
\frac{\psi}{\zeta}=1+\Theta \frac{\xi(\underline{\eta})}{X}
$$

where $\Theta=\frac{1}{z 2^{1+\alpha_{1}}}$ and $\xi(\eta)=\frac{(1-\eta)^{1+\alpha_{1}}}{\eta^{2+\alpha_{1}}}$. The degree of incrementalism is decreasing in the share of people living in a diversified city and in the total amount of innovators in the economy. This fact reflects the intuition that, for a given share $\eta$, more people generate more spillovers from diversification than from specialization. This scale effect is markedly different from the one that is commonly present in endogenous growth models, as it operates through the composition, instead of the intensity, of innovation activity.

The first condition needed in order to have a perfect sorting equilibrium is that innovators 
in $k^{d}$ must find it optimal to engage in informal interaction upon receipt of an idea (note that innovators in specialized cities will always prefer to implement the idea through a conventional invention, as they do not have access to the opposite technology class). This condition can be written as:

$$
\mathcal{D}_{k^{d}}^{\tau}=\frac{z\left\{\frac{\eta X}{2} V(0)+\frac{\eta X}{2} E_{\Delta}[\beta(\Delta)]\right\}}{E_{\Delta}[\beta(\Delta)]} \geq 1 .
$$

The spatial equilibrium condition requires $W_{k^{\tau_{1}}}^{\tau_{1}}=W_{k^{d}}^{\tau_{1}}$ that is:

$$
\begin{aligned}
& -r_{k^{d}}+\alpha_{0}\left[\frac{\eta X}{2}\right]^{\alpha_{1}}\left\{\frac{\eta X}{2} V(0)+\frac{\eta X}{2} E_{\Delta}[\beta(\Delta)]\right\}= \\
= & -r_{k^{\tau_{1}}}+\alpha_{0}\left[\frac{(1-\eta) X}{2}\right]^{\alpha_{1}} E_{\Delta}[\beta(\Delta)]
\end{aligned}
$$

and specularly $W_{k^{\tau_{2}}}^{\tau_{2}}=W_{k^{d}}^{\tau_{2}}$.

Total unskilled labor used in the production of respectively non-tradables (housing) and intermediate goods is:

$$
\begin{aligned}
& N^{H}=f(\eta X)+2 f\left(\frac{(1-\eta) X}{2}\right) \\
& N^{F}=K-N^{H}
\end{aligned}
$$

A perfect sorting equilibrium can be computed using the following procedure. For any $\eta \in(0,1)$, aggregate innovation rates can be computed using (19) and total unskilled labor used in the production of non-tradables can be computed through (22). Then, the wage rate can be computed through (16), which also delivers a value for the rent in the three cities. The aggregate innovation rates can be used to compute the value of $V(0)$ and $E_{\Delta}[\beta(\Delta)]$. Finally, an equilibrium is found if both the consistency condition (20) and the spatial equilibrium condition (21) are verified.

\subsection{Calibration and Results}

We now explain how we calibrate the parameters of the model to perform our quantitative analysis.

As a first step, we must choose a functional form for the housing production function $f(\cdot)$ that is increasing and satisfies $f^{\prime \prime}\left(H_{k}\right) \geq 0$ and $\lim _{H_{k} \rightarrow 1^{-}} f^{\prime}\left(H_{k}\right)=+\infty$. A good candidate is:

$$
f\left(H_{k}\right)=\bar{f} \frac{H_{k}^{\phi}}{\left(1-H_{k}\right)^{2}}
$$

with $\bar{f}>0$ and $\phi>1$. 
We pick the value of $x$ in such a way to make the total supply of skilled labor equal to $36 \%$ of the total labor force, that is, the share of college graduates in the US labor force. Having normalized the mass of unskilled labor to $K=3$, this gives a value of $x$ equal to 0.56 and a total mass of innovators $X$ equal to $x K=1.68$.

Since the estimation of intra-sectoral technological spillovers is beyond the purposes of this paper, we rely on the extensive empirical literature on the subject to calibrate the elasticity of patenting with respect to neighbor innovators, $\alpha_{1}$. Bloom et al. (2013) estimate the elasticity of a firm's patenting with respect to research and development carried out by technologically close firms to range between 0.407 and 0.530 , but these estimates neglect the spatial dimension of technological interactions. Matray (2014) estimates the local elasticity of patenting activity of small firms to patenting of geographically close listed firms to range between 0.17 and 0.24 . When controlling for technological proximity (Jaffe distance) the implied elasticities are substantially larger. In our baseline analysis, we set $\alpha_{1}=0.407$, which corresponds to the estimate in Bloom et al. (2013) from an instrumented regression, but we experiment with different values of $\alpha_{1}$ to see how our results are affected.

We normalize the step size of unconventional innovation to $\lambda_{0}=0.015$ and estimate all the other parameters that control the innovation process. The value of $\rho=0.05$ is standard in the literature and corresponds to an annual discount rate of 0.95 .

The remaining parameters $\left(\lambda_{1}, \bar{f}, \phi, b, z, \alpha_{0}\right)$ are set to minimize the distance between some observed moments and their model generated counterpart, as shown in Table 4.2, according to the following metric:

$$
D=\sum_{j} \frac{\mid \text { model }_{j}-\text { data }_{j} \mid}{\mid \text { data }_{j} \mid} .
$$

The resulting parameter values are listed in Table 4.1

We target moments regarding the average relative cost of housing in areas with more versus less than 1,000 people/ $\mathrm{km} 2$, the average share of income that goes to housing for the two categories of locations (these moments help us pin down the parameters controlling the locational choice and the cost of housing). We also target an aggregate growth rate of output of $2 \%$ per year. Finally, we target the labor share and the average number of citations received by a patent issued over a given time horizon (these two moments pin down the parameters that control the relative supply of conventional and unconventional innovation). ${ }^{17}$ All targeted moments are matched very closely by our calibration.

To complete our calibration, we allow for the possibility that a flow of conventional innovation arrives exogenously at a given Poisson rate $e>0$ (as a share of total domestic innovation). We

\footnotetext{
${ }^{17}$ In the Appendix, we derive the analytical expression that allows to compute the expected number of citations received by a patent over a time horizon $T$ (which we set to 12 and use to match the average number of citations received by 2014 by a patent issued in 2002).
} 


\begin{tabular}{c|c|c} 
Parameter & Value & Source/Target \\
\hline \hline \multicolumn{3}{c}{ Assigned Parameters } \\
$\lambda_{0}$ & 0.05 & Annual discount factor 0.95 \\
$x$ & 0.015 & Normalized \\
$q$ & 1.68 & 36\% of skilled workers \\
& 0.9 & Share of unconv. from H \\
$\alpha_{1}$ & 0.407 & Spillover elasticity \\
& \multicolumn{2}{c}{ from Bloom et al. (2013) } \\
\hline \multicolumn{3}{c}{ Calibrated Parameters } \\
\hline$\lambda_{1}$ & 0.0328 & Step factor conv. \\
$\bar{f}$ & 0.018 & Housing \\
$\phi$ & 4.911 & Efficiency of search \\
$z$ & 0.404 & Appropriability of conv. \\
$b$ & 0.579 & Poisson arrival of ideas
\end{tabular}

Table 4.1: Parameter Values

\begin{tabular}{c|cc} 
Moment & Data & Model \\
\hline \hline Relative Rent H/L & 1.43 & 1.45 \\
L Share of Income in Rent & $20 \%$ & $20 \%$ \\
H Share of Income in Rent & $27 \%$ & $26.8 \%$ \\
Average Citations Received in T=12 & 6.53 & 6.53 \\
Labor Share & 0.58 & 0.57 \\
Aggregate Growth Rate & $2 \%$ & $2 \%$
\end{tabular}

Table 4.2: Moments: Data and Model

interpret this as the arrival of incremental inventions from emerging economies. As we will argue below, this component is becoming increasingly relevant in the innovation landscape of advanced economies and our framework is suitable for studying the implications of this change for the relationship between technological progress and geography. To calibrate $e$, we take the ratio of patents whose assignee is located in China or India over the patents whose assignee is located either in the United States, India or China. Over the 11 years period of our sample, the average of this ratio is $1.94 \%$, but it shows a steady increase from $0.34 \%$ in 2000 up to $4.94 \%$ in 2010 (a more than a tenfold increase).

The model generates the geographical sorting of innovation illustrated in Figure 4.2. The diversified city has a density of population equal to 0.58 , compared to 0.55 of the specialized city. This implies a degree of incrementalism of 22.11, namely, every unconventional innovation receives on average 22.11 incremental improvements before being replaced by another unconventional idea. The estimated parameter for the efficiency of the search process $z$ is 0.4 . This relatively low value implies that informal interactions are substantially riskier and must be com- 

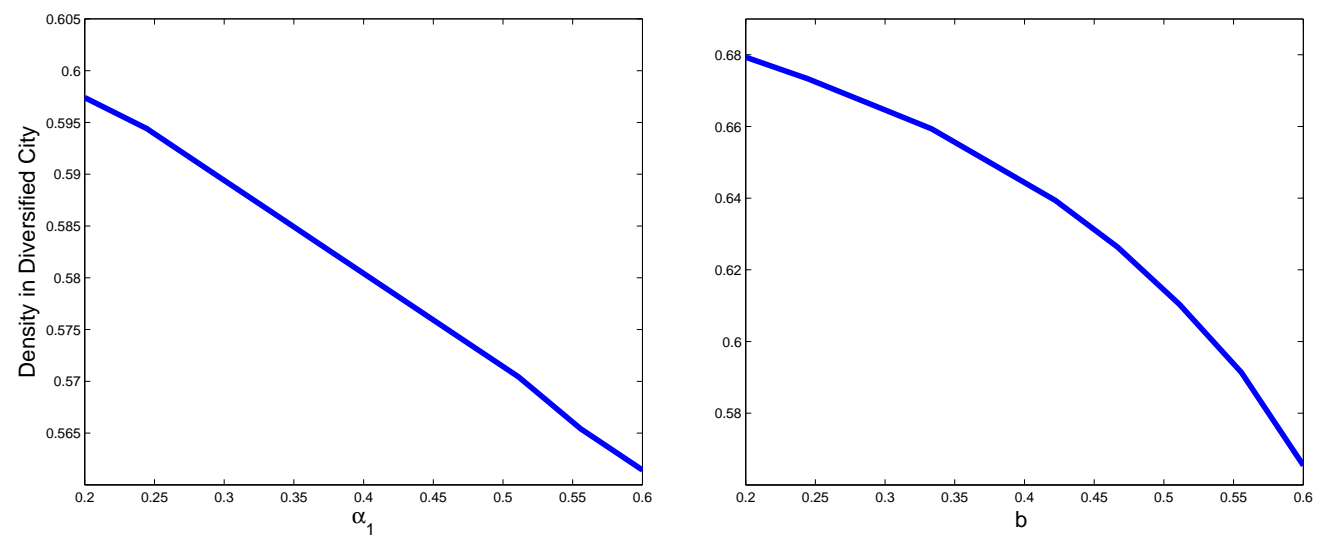

Figure 4.3: Comparative Statics. The left panel shows the equilibrium density in the diversified city for different values of the intra-sectoral elasticity of technological spillovers, $\alpha_{1}$. The right panel shows the equilibrium density in the diversified city for different values of the degree of appropriability of conventional innovation, $b$.

pensated by a high price of unconventional innovation. The calibration further reveals that the step factor of conventional ideas, $\lambda_{1}$, is substantially larger than the step factor assumed for unconventional innovation. An important implication of this result is that, other things being equal, there is a trade-off between growth and creative destruction. We will analyze this tradeoff more in detail when we come to the planner's problem. Intra-field technology spillovers are stronger in the sparse and specialized location than in the dense/diversified one, namely $X_{k^{\tau} h}^{\tau_{h}}>X_{k^{d}}^{\tau_{h}}$, but nonetheless the returns from unconventional innovation are sufficiently large to equalize welfare in the two locations (and compensate for the rent differential).

Figure 4.3 shows some comparative statics with respect to some key parameters that control the process of innovation. In the left panel we plot the equilibrium density in the diversified city for different values of the elasticity of intra-sectoral local spillovers, $\alpha_{1}$. An increase in the strength of local spillovers raises the returns from relocating towards a highly specialized area. This in turn induces innovators to leave the diversified city and move towards the specialized ones. In the right panel, the density of the diversified city is plotted against different value for the degree of appropriability of conventional innovation $b$. Again, higher appropriability reduces the relative returns from creative destruction and induces a reallocation of innovation towards specialized cities. This suggests a first source of discrepancy between the social optimum and the equilibrium outcome, as the optimal allocation should be naturally independent from the degree of appropriability.

The equilibrium allocation conceals many externalities. The static allocation of labor across different varieties is inefficient, as the Cobb-Douglas technology of the final good producer prescribes that labor should be evenly allocated across different varieties for a given technological frontier $\left(a_{i}^{L}\right)_{i \in[0,1]}$. However, the heterogeneity in the structure of markups implied by (6) in- 
duces an allocation of labor in which product lines with a high technological lead employ less labor than firms with a small lead. As noted by Peters (2013), this static misallocation is tightly related to the dynamic properties of the economy (entry or, in the context of this model, unconventional innovation). In the next section, we consider the optimal policy of a constrained planner who can implement place-based policies that affect the locational choice of individuals. We show that in choosing the optimal level of urbanization, the planner balances the positive effects of an increase creative destruction with the negative effects of an increase in geographical concentration and the resulting congestion costs, and possibly the negative impact on the growth rate of output.

\subsection{Planner's Problem}

In this section, we analyze the optimal local policy of a constrained planner who can tax the innovators and provide local-based subsidies. The planner can affect the locational choice of innovators, but cannot effectively control pricing and production operations carried out by monopolistic firms. He can impose net taxes $\left\{T_{k}^{\tau_{h}}\right\}$ on innovators of class $\tau_{h}$ living in city $k$, with the objective of maximizing the utility of the representative consumer along the optimal balanced growth path.

The planner solves:

$$
\max _{\left\{T_{k}^{\tau}\right\}} \int_{0}^{\infty} e^{-\rho t}\left[\log \left(c_{0} e^{g t}\right)\right] d t
$$

subject to

$$
\begin{aligned}
c_{0} & =\log \left(N^{F}\right)+\int_{0}^{1} \log \left(a_{i, t}^{L}\right) d i+\int_{0}^{1} \log \left(\mu_{i, t}^{-1}\right) d i-\log \left(E\left[[\mu(\Delta)]^{-1}\right]\right) \\
g & =\lambda_{1} \psi+\lambda_{0} \zeta \\
E\left[[\mu(\Delta)]^{-1}\right] & =\frac{\zeta\left(1+\lambda_{1}\right)}{\left(1+\lambda_{0}\right)\left[\left(1+\lambda_{1}\right) \zeta+\lambda_{1} \psi\right]} \\
E\left[\log \left(\mu_{i, t}^{-1}\right)\right] & =-\left[\log \left(1+\lambda_{0}\right)+\frac{\psi}{\zeta} \log \left(1+\lambda_{1}\right)\right] \\
N^{F} & =K-\sum_{k=1}^{K} f\left(X_{k}\right) \\
\zeta & =\sum_{k=1}^{K} \sum_{\tau \in \mathcal{T}} d\left(X_{k}^{\tau}\right) z X_{k}^{\tau} X_{k}^{-\tau} \mathbb{1}_{\left\{\mathcal{D}_{k}^{\tau} \geq 1\right\}} \\
\psi & =\sum_{k=1}^{K} \sum_{\tau \in \mathcal{T}} d\left(X_{k}^{\tau}\right)\left\{X_{k}^{\tau} \mathbb{1}_{\left\{\mathcal{D}_{k}^{\tau}<1\right\}}+z\left(X_{k}^{\tau}\right)^{2} \mathbb{1}_{\left\{\mathcal{D}_{k}^{\tau}<1\right\}}\right\} \\
X_{k}^{\tau}>0 & \Leftrightarrow k \in \arg \max \left\{W_{k}^{\tau}-T_{k}^{\tau}\right\}_{k=1}^{K} \quad \forall \tau \in \mathcal{T}
\end{aligned}
$$

In the analysis of the planner's choice, we assume that the planner can affect the equilibrium 
only locally, that is, she can design a system of incentives that changes the equilibrium allocation, while keeping the spatial sorting of innovators consistent with a perfect sorting equilibrium similar to the one illustrated in Figure $4.2 .^{18}$

Once the perfect sorting structure is assumed, by substituting the constraints in (23), solving the integral and getting rid of the additive and multiplicative constants, one can reduce the planner's problem to the choice of a single variable $\eta \in(0,1)$, which represents the share of innovators living in the diversified city. Once the optimal allocation is computed, the planner can implement it by choosing a simple location-specific lump-sum transfer from people in specialized cities to individuals in the diversified location. Formally, one can state the following:

Proposition 2. Assume the planner is restricted to symmetric allocations satisfying perfect sorting, as in Definition 1. Then, the planner's problem (23) reduces to:

$$
\max _{\eta} \frac{\lambda_{1} \psi+\lambda_{0} \zeta}{\rho}+\log \left(K-N^{H}\right)-\frac{\log \left(1+\lambda_{1}\right) \psi}{\zeta}-\log \left(\frac{\zeta}{\zeta\left(1+\lambda_{1}\right)+\psi \lambda_{1}}\right)
$$

subject to

$$
\begin{aligned}
\zeta & =2 z \alpha_{0}(\eta X)^{2+\alpha_{1}} \\
\psi & =\zeta+2 \alpha_{0}\left[\frac{(1-\eta) X}{2}\right]^{1+\alpha_{1}} \\
N^{H} & =f(\eta X)+2 f\left(\frac{(1-\eta) X}{2}\right) \\
\mathcal{D}_{k^{d}}^{\tau} & \geq 1 \\
\mathcal{D}_{k^{\tau}}^{\tau} & <1 .
\end{aligned}
$$

\begin{tabular}{|c|c|c|}
\hline \multicolumn{3}{|c|}{$\begin{array}{l}{ }^{18} \text { In other words, we assume the planner can affect locational choices through } \\
\text { allocate initial monopoly power consistently with the balanced growth path solut } \\
\text { the static allocation of labor across intermediate firms along the balanced growth }\end{array}$} \\
\hline & Equilibrium & Planner \\
\hline Growth & 0.02 & 0.017 \\
\hline Density in $\mathrm{H}$ & $58.04 \%$ & $70.43 \%$ \\
\hline Density in L & $55.28 \%$ & $49.09 \%$ \\
\hline Average Lead & 22.23 & 11.96 \\
\hline Static Distortion & -0.175 & -0.056 \\
\hline Labor Share & $57.9 \%$ & $71.3 \%$ \\
\hline Cons. equiv. & 0 & $+0.31 \%$ \\
\hline
\end{tabular}

As we show below, under the baseline calibration, the planner will choose to allocate more

Table 4.3: Equilibrium and Planner: Statistics 
people towards the diversified city. It is worth noting that the benefit from urbanization do not come directly from classical agglomeration externalities. On the contrary, the high-density city offers less direct spillovers than the sparse, specialized one. The planner is instead pushing towards higher density in the diversified city in an attempt to affect the composition of innovation activity. At the social optimum, innovators in the diversified cities will have a baseline utility which is lower than the one in the sparse locations. Hence, the optimal policy can be implemented simply by providing a net tax that perfectly compensates for the utility differential between the two areas.

Table 4.3 summarizes the comparison between the market allocation and the planner's optimal policy. The planner chooses to decrease growth by 0.3 percentage points, to increase the density of population in the diversified city from $58 \%$ to $70 \%$ and to reduce the static distortion and the average markup. This also results in lower aggregate profits and higher labor share. The resulting welfare gain is 0.31 percentage points in annualized consumption equivalent units.

\subsection{Welfare Decomposition}

The log-utility assumed for the representative household allows to decompose the planner's objective function into the sum of three distinct terms:

$$
W^{P}=\underbrace{\frac{\lambda_{1} \psi+\lambda_{0} \zeta}{\rho}}_{\text {Growth }}+\underbrace{\log \left(K-N^{H}\right)}_{\text {Congestion }}-\underbrace{\left[\frac{\log \left(1+\lambda_{1}\right) \psi}{\zeta}+\log \left(\frac{\zeta}{\zeta\left(1+\lambda_{1}\right)+\psi \lambda_{1}}\right)\right]}_{\text {Static Misallocation }} .
$$

The first term refers to the fact that the planner, by affecting the locational choice of innovators, can change both the innovation intensity and composition. In our calibration, the fact that $\lambda_{1}>\lambda_{0}$ implies that there is a trade-off between shifting the composition of innovation towards more creative destruction and increasing the growth rate of output. The second term reflects the fact that by increasing the concentration or the dispersion of innovators across the different locations, the planner diverts unskilled labor from the production to the housing sector. This is a straightforward implication of the convexity of the housing cost function and can be directly interpreted as the congestion cost that different degrees of urbanization impose on the society. The last term depends solely on the degree of incrementalism, $\frac{\psi}{\zeta}$, and refers to the fact that by affecting the locational choice of innovators, the planner is changing the composition of innovation and, as a consequence, the static distortion that the dispersion of markups imposes on the allocation of labor across firms.

Figure 4.4 shows the relative contribution of the three terms to the improvement in welfare from the equilibrium to the planner allocation. The planner sacrifices growth and congestion costs in order to induce higher concentration in the diversified city, with the result of inducing 


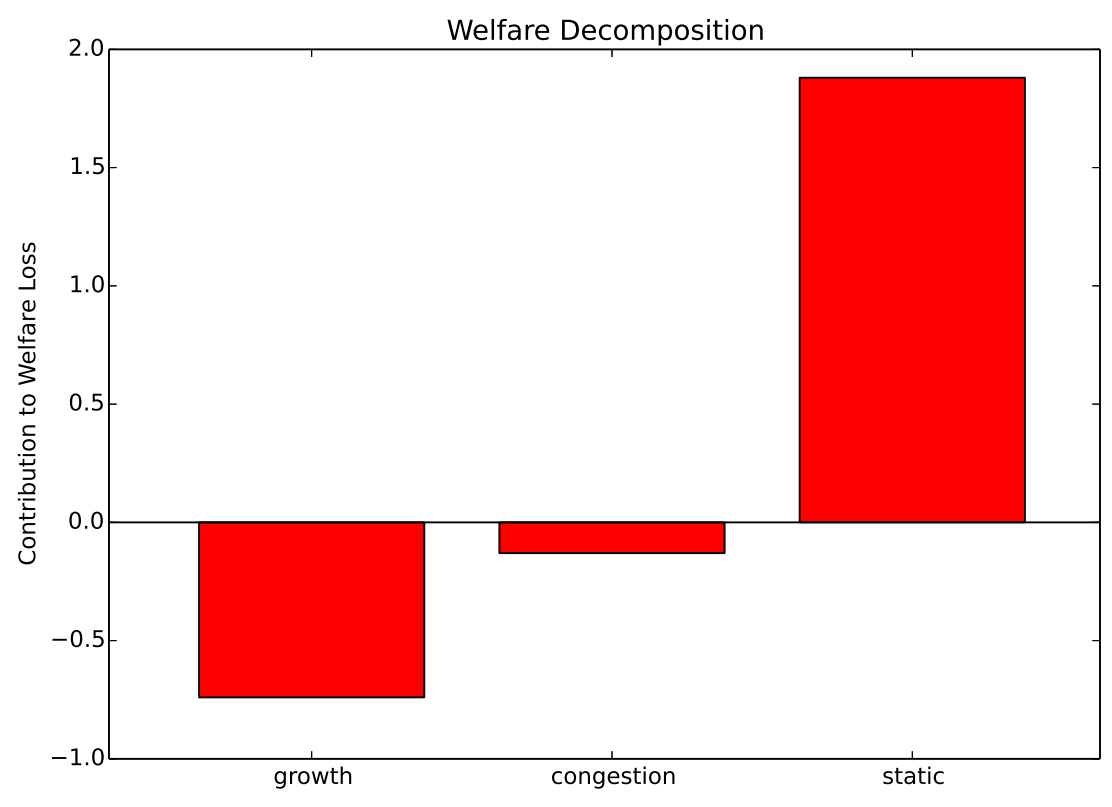

Figure 4.4: The figure shows the contribution to the welfare loss in equilibrium compared to the planner allocation. By construction, the sum of the three columns is one.

higher creative destruction and lowering the static misallocation.

\subsection{Innovation and Globalization}

It is commonly understood that globalization in the last decades has deeply reshaped the comparative advantage of advanced countries in the world economy. The common wisdom is that, since most of the manufacturing operations can be easily relocated to low-wage countries, we should expect to observe innovation to be increasingly concentrated in skill-rich, high-wage countries. However, a first glance at the evolution of the geographical origin of the innovation patented in the United States over the last decade suggests a different story. Patents filed by assignees in the two most representative emerging economies, China and India, have gained substantial momentum in the US innovation landscape, going from less than $0.5 \%$ to almost $5 \%$ of the total patents issued by the USPTO. Over the same period, the share of patents filed by the two main technological competitors, Japan and Germany, has shown no visible trend, oscillating around $36 \%$ (see Figure 4.5).

Commentators have suggested that emerging economies are increasingly contributing to global technological progress by specializing in the production of innovation characterized by a lower degree of creativity. This intuition is indeed confirmed when we look at how displaying an assignee from China or India affects the probability that a patent has an unconventional tail. 

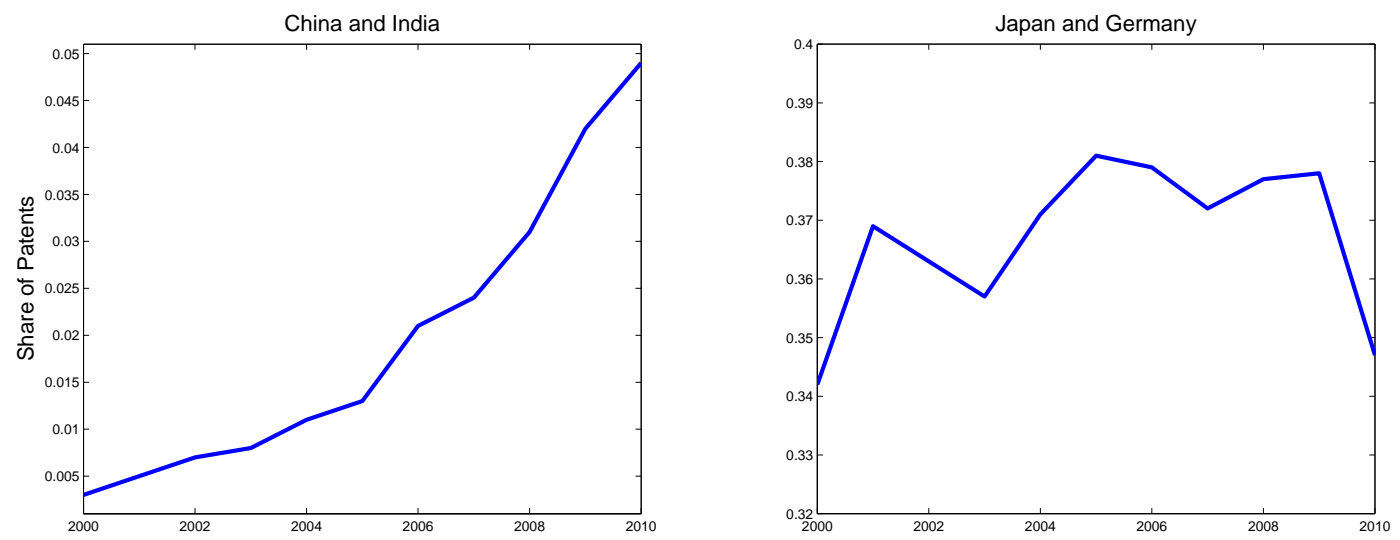

Figure 4.5: The figure shows the share of patents issued by the USPTO with assignee located in China or India (left panel) and Japan or Germany (right panel).

We restrict our sample to patents listing an institutional assignee whose location is either in the United States, India or China, and construct a dummy Emerging which is equal to one if the patent's assignee is from either China or India. We then run the following patent level logit regression:

$$
\operatorname{logit}\left(\operatorname{low}^{\text {th }} \text { perc }_{i c t}\right)=\alpha+\delta_{t}+\delta_{c}+\text { Emerging }_{i c t}+\varepsilon_{i c t}
$$

where $\alpha_{c}$ is a technology class fixed effect and $\gamma_{t}$ a time fixed effect. As shown in Table 4.4, the marginal effect of the dummy Emerging is negative, statistically significant and very large. A patent whose assignee is in China or India is $14 \%$ less likely to have an unconventional tail than a patent in the same technology class assigned to a US entity.

\begin{tabular}{c|c} 
& low $10^{\text {th }}$ perc \\
\hline \hline Emerging & $-0.1408^{* * *}$ \\
& $(0.0045)$ \\
\hline Obs. & 892,750
\end{tabular}

Table 4.4: This table show the results of a patent-level logit regression on the probability of having an unconventional tail on a dummy that is equal to one if the patent has an assignee from either China or India. Only patents with an assignee from China, India or the United States are included in the sample.

To understand the implications of the rise in the supply of conventional innovation from emerging economies, we run the following exercise. We assume that in the short-run the fixed cost of moving always exceeds its benefit. Under this assumption, we compute the welfare loss of an economy with a spatial allocation determined according to the supply of external conventional innovation in 2000. We then change the rate of arrival of conventional innovation from abroad 

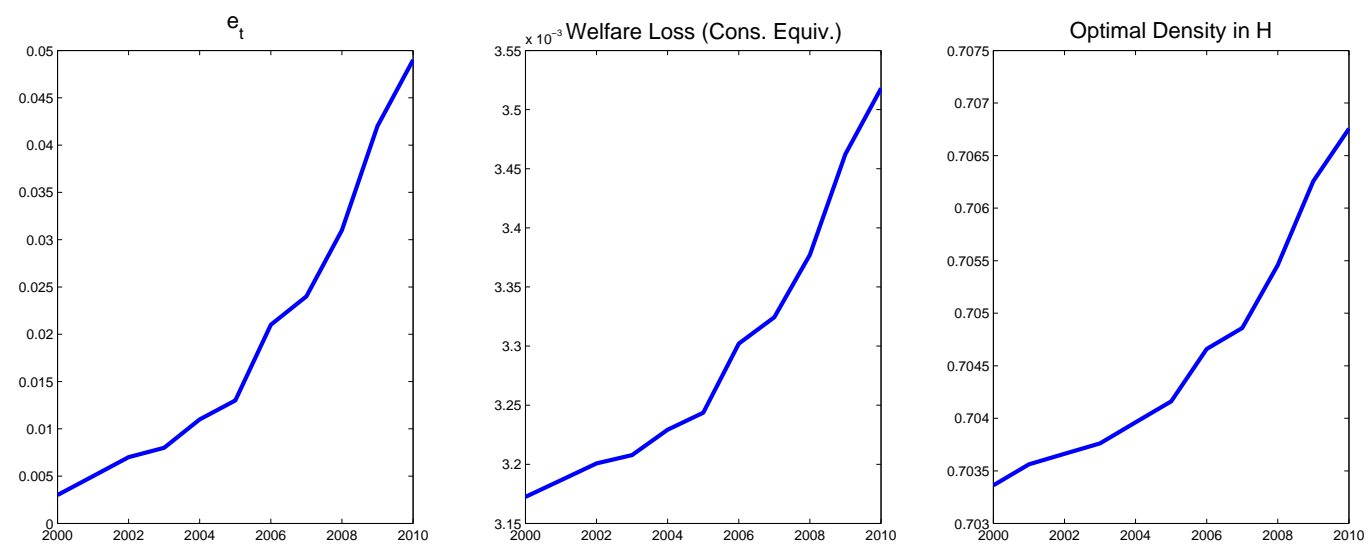

Figure 4.6: The left panel shows the values of $e_{t}$ that correspond to the shares in the left panel of Figure 4.5. The center panel shows the implied welfare loss when the geographical allocation is constrained to be the same as in the first period (2000). The right panel shows the optimal density in the diversified city. The equilibrium density is constant throughout.

according to the left panel of Figure 4.5, and compute the corresponding welfare loss while keeping the spatial allocation constant. The results are shown in the center and right panels of Figure 4.6. An increase in the arrival of conventional innovation imposes increasing costs in terms of welfare (the welfare loss in consumption equivalent goes from $0.31 \%$ to $0.35 \%$ ). The planner would relocate innovation activity towards the high-density city.

The pressure on advanced economies to boost the supply of creative ideas is visible in a variety of local policies and spontaneous trends that have emerged recently. Katz and Wagner (2014) argue that while the landscape of innovation in the United States has been dominated for decades by spatially isolated suburban areas accessible only by car and hardly conducive of informal interactions, "a new complementary urban model is now emerging, giving rise to what we and others are calling "innovation districts." These districts, by our definition, are geographic areas where leading-edge anchor institutions and companies cluster and connect with start-ups, business incubators and accelerators. They are also physically compact, transit-accessible, and technicallywired and offer mixed-use housing, office, and retail". Innovation districts are emerging in under-utilized areas of industrial cities such as Cleveland, Detroit, Philadelphia, St. Louis and are developing rapidly in other cities like Boston, Chicago and Portland. The public sector actively intervenes in this process by investing in public infrastructure (e.g. public transit and parks) and serves as a coordinating agent. The urban dimension is key: attracting diversity is perceived to be essential to this process. Diversity is also the key to a variety of genuinely urban phenomena such as coworking (Moretti, 2012). The desire of self-employed youth to co-locate with other people irrespectively of their field of specialization can actually reflect the demise of traditional professions and the increasing pressure to develop new models of business that can 
fully take advantage of the opportunities of a technologically integrated world. In July 2014, the Chicago Tribune referred to coworking spaces as to the "front lines of Chicago's new economy". ${ }^{19}$

Our analysis suggests that the returns to creative ideas rise considerably when the availability of incremental innovation increases. Intuitively, the incentives to conceive a new smartphone app are higher when the availability of programmers able to implement it is higher. Although there are many factors that can be perceived as responsible for this "urban revolution" in the geography of innovation, our analysis highlights a potentially important channel that would deserve a more in-depth analysis. This is left to future research.

\section{Conclusion}

Understanding the process through which creative ideas are generated is crucial to fully exploit the comparative advantage of advanced economies in today's world. In this paper, we explore a specific aspect of this process, namely how the economic geography shapes the creative content of innovation. We show that innovation sorts in the territory according to its degree of conventionality. In particular, high-density areas specialize in producing unconventional technology. We do this by assembling a new dataset of georeferenced patents and by assigning a measure of creativity which is novel to the macro literature on innovation. Our empirical analysis reveals that the combination of ideas embedded into inventions is determined by the local technology mix. This supports the hypothesis that knowledge spillovers resulting from informal interactions are a key component of the innovation process. High-density areas promote diversification and facilitate informal interactions, resulting in a higher degree of unconventionality in innovation. Our analysis reconciles the fact that a big portion of innovative activity takes place outside cities with the common wisdom, rooted in the literature, that density is an important catalyzer of innovative activity.

We integrate these findings in an endogenous growth model with spatial sorting and heterogeneous innovation. In our setting, the choice between producing conventional and unconventional ideas depends on their relative price and, crucially, on the local degree of density and diversification. In equilibrium, sparse and specialized cities coexist with dense and diversified ones. This in turn determines the spatial sorting of innovative activity. The composition of innovation determines the balance between growth, static misallocation of resources and congestion costs, which in equilibrium is suboptimal. Our analysis reveals that a constrained planner would sacrifice growth and congestion costs, increase urbanization, promote the creation of unconventional ideas and reduce the monopolistic distortions.

This type of intervention becomes even more welfare improving if there is an increase in the

\footnotetext{
19"Inside views on Chicago's coworking spaces", Chicago Tribune, July 15, 2014.
} 
equilibrium returns from creative ideas, as it might result from an expansion in the supply of conventional innovation from emerging economies. This can help rationalize the recent shift in the geography of innovation in the United States, where densely populated urban centers are emerging as the main hubs in the landscape of innovation. It also provides support to localbased policies aimed at attracting cutting-edge technological firms through the establishment of startup incubators in urban areas.

Further research should be devoted to understand the locational choice of large firms and whether these are subject to the same type of incentives as small, typically more unconventional firms. Another promising avenue would be exploring what other cultural and economic factors can be held responsible for the "urban revolution" that is rapidly reshaping the economic geography of advanced economies. 


\section{References}

[1] Akcigit, Ufuk, and William R. Kerr. 2010. "Growth Through Heterogeneous Innovations." NBER Working Paper No. 16443.

[2] Acemoglu, Daron, Ufuk Akcigit, and Murat A. Celik. 2014. "Young, Restless and Creative: Openness to Disruption and Creative Innovations." NBER Working Paper No. 19894.

[3] Audretsch, David B., and Maryann P. Feldman. 1996. "R\&D Spillovers and the Geography of Innovation and Production." American Economic Review, 86(3): 630-40.

[4] Audretsch, David B., and Paula E. Stephan. 1996. "Company-Scientist Locational Links: The Case of Biotechnology," American Economic Review, 86(3): 641-52.

[5] Berliant, Marcus, and Masahisa Fujita. 2011. "The Dynamics of Knowledge Diversity and Economic Growth." Southern Economic Journal, 77(4): 856-84.

[6] Chetty, Raj, John N. Friedman and Jonah E. Rockoff. 2014. "Measuring the Impacts of Teachers I: Evaluating Bias in Teacher Value-Added Estimates." American Economic Review, 104(9): 2593-2632.

[7] Combes, Pierre-Philippe, Gilles Duranton, Laurent Gobillon, Diego Puga and Sebastien Roux. 2012. "The Productivity Advantages of Large Cities: Distinguishing Agglomeration From Firm Selection." Econometrica, 80(6): 2543-2594

[8] Davis, Donald R., and Jonathan I. Dingel. 2014. "The Comparative Advantage of Cities." NBER Working Paper No. 20602.

[9] Davis, Donald R., and Jonathan I. Dingel. 2012. "A Spatial Knowledge Economy." NBER Working Paper No. 18188.

[10] Duranton, Gilles, and Puga, Diego. 2001. "Nursery Cities: Urban Diversity, Process Innovation, and the Life Cycle of Products." American Economic Review, 91(5): 1454-1477.

[11] Feldman, Maryann P., and David B. Audretsch. 1999. "Innovation in Cities: Science-based Diversity, Specialization and Localized Competition." European Economic Review, 43(2): 409-29.

[12] Florida, Richard, and Gary Gates. 2001. "Technology and Tolerance: The Importance of Diversity to High-Technology Growth.” The Brookings Institution Survey Series, June.

[13] Glaeser, Edward L. 1999. "Learning in Cities." Journal of Urban Economics, 46(2): 254-77. 
[14] Glaeser, Edward L. and Joshua D. Gottlieb. 2009 "The Wealth of Cities: Agglomeration Economies and Spatial Equilibrium in the United States." Journal of Economic Literature, 47(4): 983-1028.

[15] Griliches, Zvi. 1990. "Patent Statistics as Economic Indicators: A Survey." Journal of Economic Literature, 28(4): 1661-1707.

[16] Hall, Bornwyn H., Aadam B. Jaffe, and Manuel Trajtenberg. 2001. "The NBER Patent Citations Data File: Lessons, Insights and Methodological Tools." NBER Working Paper No. 8498.

[17] Jaffe, Adam B., Manuel Trajtenberg and Rebecca Henderson. 1993. "Geographic Localization of Knowledge Spillovers as Evidenced by Patent Citations." The Quarterly Journal of Economics, 108(3): 577-98.

[18] Katz, Bruce and Julie Wagner. 2014. "The Rise of Innovation Districts: A New Geography of Innovation in America." Metropolitan Policy Program at Brookings, May

[19] Klette, Tor J., and Samuel Kortum. 2004. "Innovating Firms and Aggregate Innovation." Journal of Political Economy, 112(5): 986-1018.

[20] Kogan, Leonid, Dimitris Papanikolaou, and Noah Stoffman. 2013. "Technological Innovation: Winners and Losers." NBER Working Paper No. 18671.

[21] Kogan, Leonid, Dimitris Papanikolaou, Amit Seru and Noah Stoffman., 2012, "Technological Innovation, Resource Allocation, and Growth." NBER Working Paper No. 17769.

[22] Krugman, Paul. 1991. "Increasing Returns and Economic Geography." Journal of Political Economy, 99(3): 483-99.

[23] Lucas, Robert Jr. 1988. "On the Mechanics of Economic Development." Journal of Monetary Economics, 22(1): 3-42.

[24] Marshall, Alfred. 1890. Principles of Economics. London: Macmillan and Co., Ltd.

[25] Matray, Adrien. 2014. "The Local Innovation Spillovers of Listed Firms." https://sites.google.com/site/adrienmatray/research.

[26] Moser, Petra, Alessandra Voena, and Fabian Waldinger. 2014. "German Jewish Émigrés and US Invention." American Economic Review, 104(10): 3222-55.

[27] Packalen, Mikko, and Jay Bhattacharya. 2015. "Cities and Ideas." NBER Working Paper No. 20921. 
[28] Peters, Michael. 2013. "Heterogeneous Mark-Ups, Growth and Endogenous Misallocation." http://mipeters.weebly.com/research.html.

[29] Porter, Micheal E. 1998. The Competitive Advantage of Nations. New York: Free Press.

[30] Saxenian, Annalee. 1994. Regional Advantage: Culture and Competition in Silicon Valley and route 128. Cambridge, MA: Harvard University Press.

[31] Uzzi, Brian, Satyam Mukherjee, Micheal Stringer, and Ben Jones. 2013. "Atypical Combinations and Scientific Impact." Science, 342(6157): 468-472. 


\section{A Data}

\section{Conventionality-Score: Algorithm}

Every c-score is calculated according to the following algorithm:

1. We calculate the frequency of each citation pair in the dataset. To avoid that our results are disproportionately driven by patents with a big number of citations, we weight every occurrence by the number of possible pair combinations in a certain paper. Mathematically,

$$
\text { freq }_{e m p}(i, j)=\frac{1}{N} \sum_{n=1}^{N} \sum_{m=1}^{C_{n}-1} \sum_{l=m+1}^{C_{n}} \frac{1}{\left(\begin{array}{c}
C_{n} \\
2
\end{array}\right)} \mathbb{1}_{\left\{c_{m}=i, c_{l}=j \vee c_{m}=j, c_{l}=i\right\}}
$$

where $N$ is the total number of patents in our dataset, $C_{n}$ is the total number of citations in patent $n, c_{k}$ and $c_{l}$ are the $k$-th and $l$-th citation of patent $n$, respectively, and $i$ and $j$ are the patent classes we are considering. It is easy to see that $f r e q_{e m p}(i, j)$ is a symmetric function.

2. We calculate the frequency that one would be expect a certain citation pair to occur in a certain class if the number of citations from and to a certain class were to be respected. We weight the contribution of each patent by its total number of citations. Formally,

freq $_{\text {rand }}(i, j)= \begin{cases}\sum_{h=1}^{H} \frac{N_{h}}{N} 2\left(\frac{1}{N_{h}} \sum_{g \in \mathcal{P}_{h}} \sum_{k=1}^{C_{g}} \frac{\mathbb{1}_{\left\{c_{k}=i\right\}}}{C_{g}}\right)\left(\frac{1}{N_{h}} \sum_{g \in \mathcal{P}_{h}} \sum_{k=1}^{C_{g}} \frac{\mathbb{1}_{\left\{c_{k}=j\right\}}}{C_{g}}\right) & \text { if } i \neq j \\ \sum_{h=1}^{H} \frac{N_{h}}{N}\left(\frac{1}{N_{h}} \sum_{g \in \mathcal{P}_{h}} \sum_{k=1}^{C_{g}} \frac{\mathbb{1}_{\left\{c_{k}=i\right\}}}{C_{g}}\right)^{2} & \text { if } i=j\end{cases}$

where $H$ is the total number of classes, $\mathcal{P}_{h}$ is the set of patents of class $h, C_{g}$ the number of citations of patent $g$ patent, and $c_{k}$ is the $k$-th citation of patent $g$. The first term in parenthesis in the first expression is the (weighted) empirical probability that a patent of class $i$ is cited in class $h$ if we took a citation at random from the pool of all the citations of class $h$. The second term is the (weighted) empirical probability that a patent of class $j$ is cited in class $h$ if we took a citation at random from the pool of all the citations of class $h$. The multiplication of these two terms is therefore the probability that we would observe a citation pair $(i, j)$ if we took two citations at random from the pool keeping the network of citations from class to class constant. This expression is multiplied by two for symmetry reasons. Finally, these probabilities are weighted by the frequency of each class in the universe of patents.

The second expression implements the same idea in the case $i=j$. 
3. The c-score of each citation pair is calculated as follows:

$$
c(i, j)=\frac{\text { freq }_{\text {emp }}(i, j)}{\text { frequand }(i, j)}
$$

when the c-score is smaller than 1 , the pair $(i, j)$ is observed in the data less often than what one would expect by taking the some paper in a pseudo-random fashion. We consider this a sign of novelty. On the contrary, when the n-score is bigger than 1, the pair is observed more frequently than the pseudo-random distribution. We consider this a sign of commonality.

4. We assign to each of the $\left(\begin{array}{c}C_{n} \\ 2\end{array}\right)$ different citation pairs of each paper its c-score. So that, for each paper we obtain a distribution of n-scores.

\section{Construction of the Shocks}

The arrival shock, $A_{c s t}$, in the baseline exercise was constructed as follows:

$$
A_{c s t}=\mathbb{1}\left\{\min _{i \in \mathcal{I}_{c s}^{2001}}\left(a_{i}\right)<t\right\}
$$

where $a_{i}$ is the year in which company $i$ files its first patent and $\mathcal{I}_{c s}^{2001}$ is the set of all the firms of class $c$ whose first patent in CSD $s$ was filed after 2001.

On the other hand, the weighted shock was constructed in the following way:

$$
W_{c s t}=\sum_{i \in \mathcal{I}_{c s}^{2001}} \mathbb{1}_{\left\{a_{i}<t\right\}} \frac{\text { pat filed }_{i t}}{\text { tot pat }_{s t}}
$$

where pat filed $_{i t}$ is the number of patents filed by firm $i$ at time $t$ and tot pat $t_{s t}$ is the total of patents filed in CSD $s$ in year $t$. 


\section{B Tables and Figures}

\begin{tabular}{c|c} 
Filing Year & \# Patent Grants \\
\hline 2000 & 161,388 \\
2001 & 209,259 \\
2002 & 209,957 \\
2003 & 199,752 \\
2004 & 198,383 \\
2005 & 200,204 \\
2006 & 202,601 \\
2007 & 204,957 \\
2008 & 199,802 \\
2009 & 180,558 \\
2010 & 166,985 \\
\hline Total & $2,155,901$
\end{tabular}

Table B.1: This table reports the number of patents issued from January 2002 to August 2014 and re-arranged by filing year.

\begin{tabular}{c|cc} 
& low $10^{\text {th }}$ perc & low $10^{\text {th }}$ perc \\
\hline \hline log Population & $0.0087^{* * *}$ & $0.0068^{* * *}$ \\
density & $(0.00165)$ & $(0.0018)$ \\
Chicago & & -0.0005 \\
& & $(0.0079)$ \\
Boston & & $0.0592^{* * *}$ \\
& & $(0.0117)$ \\
New York & & $0.0300^{* *}$ \\
& & $(0.0129)$ \\
San Francisco & & $0.0632^{* * *}$ \\
& & $(0.0135)$ \\
\hline State f.e. & yes & yes \\
Year f.e. & yes & yes \\
Class f.e. & yes & yes \\
\hline N. Obs & $1,058,992$ & $1,058,992$ \\
pseudo $R^{2}$ & 0.0077 & 0.0078
\end{tabular}

Table B.2: This table reports the results of a patent-level logit regression of the probability of displaying an unconventional tail on the logarithm of density and four dummy variables that correspond to the four most densely populated groups of CSD's. Standard errors are clustered at the state-year level. 


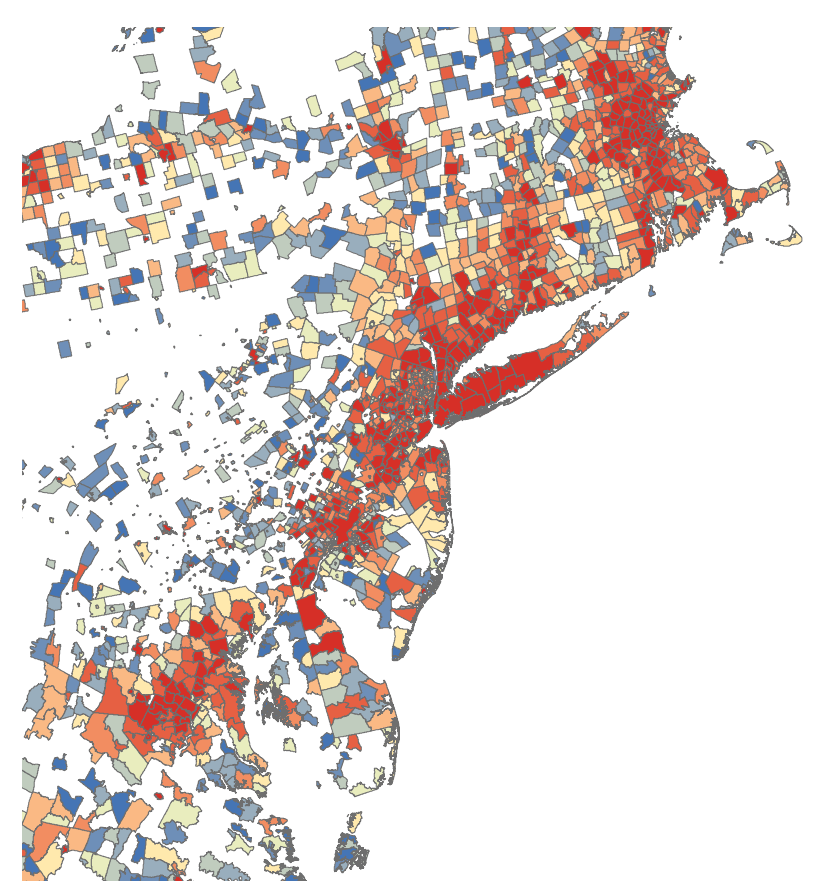

Figure B.1: The figure shows a map of county sub-divisions in the North-East Coast. Each CSD is colored according to the number of patents produced weighted by the number of citations received. The more red the higher this value; the more blue, the lower. No patents have been filed in the CSD's that are missing in the map.

\section{Model}

\section{Proof of Proposition 1}

We prove the proposition assuming that patents do not cite other inventions in $\tau_{F}$ and only cite their tail conventionality pair, $\left(\tau_{h}, \tau_{j}\right)$, with $h, j \in\{1,2\}$. When citations to $\tau_{F}$ are allowed, the proof is unchanged by the notation is more burdensome. Assume $\psi>\zeta$. Along a symmetric BGP, the share of inventions with tail citations $\left(\tau_{h}, \tau_{j}\right)$ with $h=j$ is exactly equal to $\frac{\psi}{2(\psi+\zeta)}$. On the other hand, the share of patents with tail citations $\left(\tau_{h}, \tau_{j}\right)$ with $h \neq j$ is equal to $\frac{\zeta}{\psi+\zeta}$. The theoretical frequency is proportional to the theoretical share, namely:

$$
\text { freq }_{\text {rand }}\left(\tau_{h}, \tau_{j}\right) \propto \begin{cases}\frac{1}{2} & h \neq j \\ \frac{1}{4} & h=j\end{cases}
$$

Hence:

$$
c\left(\tau_{h}, \tau_{j}\right)=\left\{\begin{array}{ll}
\frac{2 \zeta}{\psi+\zeta} & h \neq j \\
\frac{2 \psi}{(\psi+\zeta)} & h=j
\end{array} .\right.
$$

Since $\psi>\zeta$, it follows that $c\left(\tau_{h}, \tau_{j}\right)>1$ if and only if $h=j$. 


\section{Expected citations}

In the model we assume that patents receive citations when their product line receives either a conventional innovation or a creative destruction event. The share of "active" patents, that

is, patents that are still going to receive citations evolves according to the following differential equation:

$$
\frac{\dot{A}}{A}=-\zeta
$$

$A(T)$ corresponds to the probability of being still active for a patent of age $T$. Since by definition $A(0)=1$, the solution of the differential equation is:

$$
A(T)=e^{-\zeta T}
$$

The expected number of citation received between $T$ and $T+(\Delta T)$ evolves as follows (up to second order terms):

$$
\begin{gathered}
C(T+(\Delta T))=A(T)\{\zeta(\Delta T)[C(T)+1]+\psi(\Delta T)[C(T)+1] \\
+[1-\zeta(\Delta T)][1-\psi(\Delta T)] C(T)\}+[1-A(T)] C(T)
\end{gathered}
$$

which reduces to a simple differential equation:

$$
C(T)=e^{-\zeta t}[\zeta+\psi]
$$

The solution to the latter is:

$$
C(T)=-\frac{1}{\zeta}[\zeta+\psi] e^{-\zeta T}+D
$$

and, using the initial condition $C(0)=0$ :

$$
C(T)=-\frac{1}{\zeta}[\zeta+\psi] e^{-\zeta T}+\frac{1}{\zeta}[\zeta+\psi]
$$

